\title{
¿SERÍA COMPRENSIBLE LA INCLUSIÓN DEL TDAH DENTRO DE LAS DENOMINADAS \\ “ANOMALÍAS MENTALES PERMANENTES" DESCRITAS POR LA DOCTRINA PENAL TRAS EL ANÁLISIS DE LA CUESTIÓN DE IMPUTABILIDAD-INIMPUTABILIDAD?
}

\author{
Marta María Aguilar Cárceles \\ Profesora Asociada de Derecho Penal y Criminología
}

Facultad de Derecho. Universidad de Murcia

\begin{abstract}
Resumen: El presente artículo tiene por objeto analizar uno de los aspectos más tradicionales en materia de enjuiciamiento penal, concretamente el relativo a la aplicabilidad de las circunstancias modificativas de la responsabilidad criminal ante la existencia de una anomalía o alteración mental. De manera específica, la cuestión de partida se establece sobre la posibilidad de eximir de responsabilidad criminal (artículo 20.1 Código Penal) a personas con Trastorno por Déficit de Atención e Hiperactividad (TDAH), para lo cual se revisan y analizan tanto desde el punto de vista legislativo como jurisprudencial-, las psicopatologías que comúnmente han sido admitidas por la doctrina penal. Todo lo anterior resulta en una visión crítica sobre las denominadas como "alteraciones mentales permanentes", actualmente admisibles conforme al tenor literal de lo implícitamente aceptado por el legislador en el Código Penal. Se trata de una cuestión que viene a ser discutida desde la comprensión interdisciplinar de las psicopatologías.
\end{abstract}

Palabras clave: responsabilidad criminal, patologías mentales permanentes, Trastorno por Déficit de Atención e Hiperactividad (TDAH), Artículo 20.1 del Código Penal

Abstract: This article analyzes one of the most traditional issues in the criminal jurisdiction, it is the applicability of the modifier circumstances of the criminal responsibility for the existence of any anomaly or mental disorder. Specifically, the key hypothesis is established on the possible exemption of criminal liability (Article 20.1 Criminal Law) in those subjects with an Attention 
Deficit Disorder and Hyperactivity Disorder (ADHD), for which it will be revised and analyzed both legislative and jurisprudential-, the psychopathologies that have been commonly accepted by criminal law doctrine. This study leads to a critical view about what it is known as "permanent psychopathologies" by the spanish legislator in the implicit literal redaction of the Criminal Code. This question is going to be discussed and answered from an interdisciplinary understanding of psychopathologies.

Key words: criminal liability, permanent psychopathologies, Attention-Deficit Hyperactivity Disorder (ADHD), Article 20.1 Criminal Code

SUMARIO: I. INTRODUCCIÓN. II. ¿CABRÍA EXIMIR DE RESPONSABILIDAD CRIMINAL AL INDIVIDUO CON TDAH? 1. Consideraciones generales sobre el TDAH. 2. La cuestión de inimputabilidad sobre el TDAH en su comparativa con las psicopatológicas comúnmente descritas por la doctrina penal como "permanentes". 2.1. Psicosis: especial referencia al TDAH y a la Esquizofrenia (Trastornos del Espectro Esquizofrénico). 2.2. Neurosis y TDAH. 2.3. Oligofrenias y TDAH. 2.4. Psicopatías/Trastornos de la Personalidad y TDAH. 2.5. Trastorno Mental Transitorio (TMT) y TDAH. 3. Otras psicopatologías objeto de análisis. 3. 1. Trastornos Relacionados con el Uso/Abuso de Sustancias. 3.2. Trastornos del Control de los Impulsos: la impulsividad como síntoma denominador común. III. CONSIDERACIONES FINALES. BIBLIOGRAFÍA

\section{INTRODUCCIÓN}

La relevancia de centrar la cuestión en el Trastorno por Déficit de Atención e Hiperactividad (TDAH) reside precisamente en su consideración como la psicopatología del neurodesarrollo más prevalente a nivel mundial ${ }^{1}$, a lo que además se añade su elevada

\footnotetext{
${ }^{1}$ La prevalencia del TDAH se ha estimado en torno al $5 \%$ en la infancia-adolescencia y más común en varones, rebajando aquella tasa a la mitad (2.5\%) en el caso de la adultez. El propio Manual Diagnóstico de la Asociación de Psiquiatría Americana (APA) confirma este dato (www.apa.org), el cual ha sido estimado en cifras similares por diversos autores tanto del ámbito nacional como internacional; a modo de ejemplo vid. SOUTULLO ESPERÓN, C. y DÍEZ SUÁREZ, A., Manual de Diagnóstico y Tratamiento del
} 
demanda asistencial, no solo en ámbito educativo ${ }^{2}$ y sanitario, sino también a nivel jurídicopenal. Pero, ¿ por qué podría llamar la atención respecto a su relación con este último aspecto? ¿Podría llegar a vincularse el TDAH con el ámbito jurídico-penal y, en consecuencia, conseguir beneficiarse de alguna de las cláusulas de modificación de la responsabilidad criminal previstas en el Código de 1995? Esta es precisamente la cuestión objeto de discusión una vez conocidas y analizadas las psicopatologías que comúnmente define el Derecho penal como posibles beneficiarias de la aplicación de alguna de las circunstancias modificativas apreciadas en el artículo 20 y 21 del Código Penal (CP).

TDAH, Madrid, Panamericana, 2007; y HALMOY, S.; KLUNGSOYR, K.; SKJAEREN, R. \& HAAVIK, J., «Preand perinatal risk factors in adults with attention-deficit/hyperactivity disorder», Biological Psychiatry, 71, 2012, pp.474-481, respectivamente.

${ }^{2}$ Uno de los objetivos fundamentales se establece sobre la prevención, o lo que es lo mismo, sobre la intervención o paliación de las secuelas del TDAH en sus diversos ámbitos de afectación, así como en evitar consecuencias futuras generadoras de un mayor grado de discapacidad en el individuo. A modo de ejemplo, una de las medidas a llevar a cabo se sostendría sobre la necesidad del diagnóstico temprano, alertando a las administraciones sobre la trascendencia de incluir objetivos específicos en los planes de Salud Mental tanto estatales como autonómicos, así como de implementar estrategias integrales de actuación que posibiliten la igualdad y no discriminación de este colectivo a nivel escolar. La protección a menores con este tipo de dificultades académicas se ha hecho patente a lo largo de los años, comenzando por el concepto de "necesidades educativas especiales" ya introducido en 1990 mediante la Ley Orgánica General del Sistema Educativo (LOGSE). Lo hace resaltando la contemplación del término "integración” para enfatizar la particular relevancia de estos niños en el ámbito escolar, el cual se termina sustituyendo por la acepción “inclusión” a partir de la Ley Orgánica 2/2006, de 3 de mayo, de Educación (LOE). Ahora bien, la citada Ley de 2006 no incluía a los menores con TDAH dentro del grupo de alumnado con particular necesidad de evaluación y apoyo, aspecto que queda subsanado desde el año 2013. A partir de la citada fecha, con la entrada en vigor de la Ley Orgánica de Mejora de la Calidad Educativa (LOMCE), se hace mención expresa al TDAH; concretamente, refiere el párrafo segundo del artículo 71 que «corresponde a las Administraciones educativas asegurar los recursos necesarios para que los alumnos y alumnas que requieran una atención educativa diferente a la ordinaria, por presentar necesidades educativas especiales, por dificultades específicas de aprendizaje, TDAH, por sus altas capacidades intelectuales, por haberse incorporado tarde al sistema educativo, o por condiciones personales o de historia escolar, puedan alcanzar el máximo desarrollo posible de sus capacidades personales $y$, en todo caso, los objetivos establecidos con carácter general para todo el alumnado». A lo anterior se une la noción expresa efectuada en el artículo 73 sobre lo comprensible por alumnado con necesidades educativas especiales; a este respecto, será «raquel que requiera, por un periodo de su escolarización o a lo largo de toda ella, determinados apoyos y atenciones educativas específicas derivadas de discapacidad o trastornos graves de conducta», todo lo cual ha supuesto un considerable avance. Más información en: http://www.mecd.gob.es/servicios-al-ciudadano$\mathrm{mecd} /$ participacion-publica/lomce.html 
Lo cierto es que se podría empezar discutiendo qué se entiende por patologías mentales permanentes desde la doctrina penal y cómo en ello ha derivado su interpretación -a partir de lo implícitamente redactado por el legislador-, para continuar analizando cuáles son aquéllas alteraciones comúnmente incluidas como causa de exención/atenuación de responsabilidad y si, efectivamente, habría congruencia entre la teoría y la práctica jurisprudencial.

Dicho ello, los principales interrogantes no deben pasar inadvertidos al conocimiento de los siguientes planteamientos:

i) El análisis de lo contemplado en el Código Penal de 1995 para la presencia de las alteraciones o anomalías mentales, para lo cual el legislador prevé una cláusula que, en su redacción expresa, poco delimita aquéllas patologías (artículo $20.1 \mathrm{CP}$ ).

ii) El examen de lo comprensible por "patologías mentales permanentes" desde la doctrina penal a partir de lo deducible del Código Penal.

iii) La aplicabilidad de lo detallado por el legislador y lo descrito por la doctrina penal por parte de los Tribunales españoles

Todo ello conduce a la necesidad de una triple comprobación legislativa-doctrinaljurisprudencial acerca del tratamiento de la patología mental por el Derecho penal, debiendo determinar si los planteamientos teórico-prácticos efectuados en este ámbito se dirigen o no en la misma dirección. Como se estudiará con más detenimiento, no es infrecuente hallar incongruencias entre dichos sectores, debiendo en todo caso puntualizar lo que podría o no incluirse al amparo del artículo previamente referido. Así, si bien desde el punto de vista teórico el legislador aboga por una cláusula abierta sobre las psicopatologías objeto de inclusión, la doctrina determina cuáles de aquéllas podrán tener mayor cabida en cuanto a la exención de responsabilidad, a lo que en última instancia se une la aplicación de lo emanado 


\section{Revista Internacional de \\ Doctrina y Jurisprudencia}

por los Tribunales a raíz de la concreta apreciación o no de algunas de las patologías ya estudiadas por aquélla doctrina ${ }^{3}$. A modo aclaratorio se presenta el siguiente esquema:

Esquema 1. Influencia de la comprensión de la patología mental desde la triple perspectiva legislativa-doctrinal-jurisprudencial ${ }^{4}$.

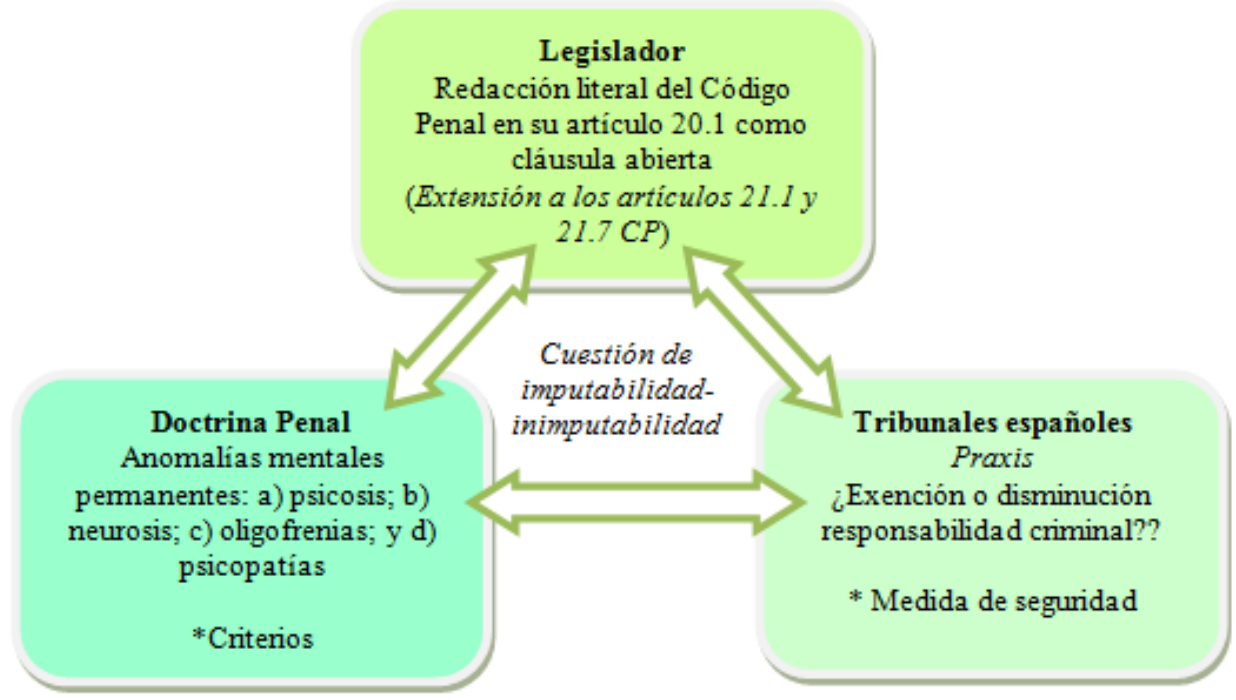

Partiendo del examen legislativo y jurisprudencial, así como de los imprescindibles matices emanados de la doctrina penal, lo cierto es que no podría ofrecerse una respuesta pacífica sobre cuáles son exactamente aquéllas alteraciones mentales que, estando presentes en el sujeto podrían suponerle la exención o disminución penal, pues la mera denominación diagnóstica no implicará directamente su aplicabilidad. Es más, incluso podría llegar afirmarse que dos sujetos con idéntico diagnóstico -en cuanto a síntomas descriptivos se refiere-, no tendrán por qué compartir consecuencias penales similares.

\footnotetext{
${ }^{3}$ Se busca principalmente la existencia de reciprocidad y coherencia en las decisiones efectuadas en cualquiera de los sectores señalados.

${ }^{4}$ Elaboración propia.
} 
Ante ello, son muchos y variados los factores que deben considerarse, debiendo comenzar por averiguar la efectiva relación entre la "disfunción" cognitiva y volitiva y el hecho cometido, así como la coincidencia temporal entre ambos, todo ello bajo el prisma del modelo mixto o de los requisitos psicobiológicos exigibles del que actuó en tal sentido.

Indicado lo anterior, para poder ofrecer una respuesta contundente a la cuestión de la posible cabida del sujeto con TDAH dentro de las patologías mentales permanentes se procederá a seguir el esquema previamente indicado, para lo cual se analizará la probabilidad de su inclusión en el Código Penal simultáneamente a su comparativa con las patologías admisibles por la doctrina penal.

\section{II. ¿CABRÍA EXIMIR DE RESPONSABILIDAD CRIMINAL AL INDIVIDUO CON TDAH?}

La razón del análisis del TDAH en comparación con otras alteraciones no es otra que el haber hallado su vinculación sintomática con la carrera criminal, aspecto que tiende a incrementar la preocupación social a sabiendas de su definición como la psicopatología del neurodesarrollo más prevalente en la infancia, así como de su elevada presencia co-ocurrente con determinados trastornos mentales relacionados con las alteraciones de conducta y comportamiento perturbador.

En general, la cronificación de las alteraciones llevará aparejada, en muchas ocasiones, la severidad de la manifestación sintomática, lo que dificultaría la intervención y prevención posterior en aquellos casos en que la actividad delictiva es un incentivo del mismo cuadro patológico. A este respecto, entiendo que sería principalmente el conjunto de estos cuadros relacionados con la criminalidad, como pudiera ser alguno de los descritos bajo la denominación de "trastornos disruptivos, del control de los impulsos y de conducta", o de aquellos relacionados con los trastornos de la personalidad o por uso/abuso de sustancias, los 
que peores resultados acarrearían respecto a los fines del Artículo 25.2 de la Constitución Española.

Es por ello que esta sección se divide en dos bloques generales, detallando en el primero lo concerniente a su vinculación con la carrera criminal así como algunos aspectos esenciales de dicha patología, para proseguir estrictamente con el segundo bloque desarrollando aquéllos elementos que competen al ámbito estrictamente de actuación penal, pues de otro lado carecería de sentido comparar el TDAH con el resto de trastornos sin su previo conocimiento. Aspecto este último que podría llevar al empleo de denominaciones de ciertas psicopatologías como sinónimos cuando en realidad no lo son y, en consecuencia, poder incluso cuestionarse la aplicación del artículo 20.1, 21.1 o 21.7 de Código Penal.

\section{Consideraciones generales sobre el TDAH}

Como se acaba de advertir, el foco de interés sobre el TDAH reside en comprender que las consecuencias derivadas del cuadro podrían, a largo plazo, llegar a vincularse con alteraciones conductuales más severas, reprochables socialmente, e incluso ilícitas ${ }^{5}$. No obstante, antes de dar comienzo al análisis de la cuestión referida con anterioridad, baste indicar que la hipótesis de partida pasa obligatoriamente por reconocer el TDAH como una psicopatología mundialmente amparada en los Manuales Internacionales.

Tanto desde la Organización Mundial de la Salud (OMS), con su Clasificación Internacional de Enfermedades y Problemas de Salud Relacionados en su Décima Edición (CIE10) ${ }^{6}$, como desde la Asociación de Psiquiatría Americana (APA), con su Manual Diagnóstico y

\footnotetext{
${ }^{5}$ MORILLAS FERNÁNDEZ, D.L. y AGUILAR CÁRCELES, M.M., «El inicio de la carrera criminal en menores infractores con Trastorno por Déficit de Atención e Hiperactividad (TDAH)», en F. Miró Llinares, J.R. Agustina Sanllehí, J.E. Medina Sarmiento y L. Summers (Eds.), Crimen, oportunidad y vida diaria. Libro Homenaje al Profesor Dr. Marcus Felson, Madrid, Dykinson, 2014, pp.457-492.

${ }^{6}$ World Health Organization (WHO) -Organización Mundial de la Salud (OMS)-. Recurso electrónico disponible en: http://www.who.int/topics/mental_disorders/en. Habría que decir que la última Revisión de la Clasificación Internacional de Enfermedades podría también definirse como la "Clasificación
} 
Estadístico de los Trastornos Mentales en su Quinta Edición (DSM-5) ${ }^{7}$, el TDAH se reconoce como una psicopatología de evidente impacto en los primeros años de vida, siendo además una de las alteraciones en la infancia que presenta un mayor índice de prevalencia, aspectos que se detallan seguidamente conforme al último de los Manuales referidos ${ }^{8}$.

Diagnosticado en los primeros años de vida bajo la apreciación de síntomas de inatención, hiperactividad e impulsividad, se define como una psicopatología que interfiere en diversas áreas del funcionamiento y desarrollo del individuo, lo que resultaría -cuando la intervención no es temprana o no es la adecuada-, en un conjunto de consecuencias que podrían llegar a cronificarse. Como ejemplo de la manifestación y secuelas del trastorno destacarían, entre otros, la afectación del rendimiento académico, problemas en la relación con los compañeros, rechazo por parte de terceros, alteración de la autoestima, comorbilidad o presencia co-ocurrente de otras psicopatologías, dificultades de adaptación al medio laboral durante la adultez ${ }^{9}$, peor ajuste social con los iguales ${ }^{10}$, así como otro conjunto de patrones disfuncionales relacionados con conducción.

Internacional de Enfermedades y Problemas de Salud Relacionados", destacando la disponibilidad de dos versiones, una relativa correspondiente a la Guía de Descriptores Clínicos y Diagnósticos, y la otra referente a los Criterios Diagnósticos de Investigación. WORLD HEALTH ORGANIZATION (WHO), International Statistical Classification of Diseases and Related Health Problems, Tenth Revision (ICD-10), World Health Organization, 1992. Baste indicar que actualmente se encuentra el borrador de la Undécima Edición (CIE-11), previsto para 2015-2017/2018.

${ }^{7}$ AMERICAN PSYCHIATRIC ASSOCIATION (APA), Diagnostic and Statistical Manual of Mental Disorders, Fifth Edition (DSM-5), Washington D.C., American Psychiatric Association, 2013, p.20. Información para complementar con la CIE-10, referencia WORLD HEALTH ORGANIZATION (WHO), International Statistical Classification of Diseases and Related Health Problems, Tenth Revision (ICD-10), World Health Organization, 1992. Version 2010 disponible en: www. http://apps.who.int/classifications/icd10/browse/2010/en

${ }^{8}$ La justificación de analizar el TDAH a partir de los criterios establecidos por la APA se fundamenta en diversos aspectos, siendo los más evidentes su difusión a nivel mundial, su empleo en investigación y en el ámbito académico-universitario, así como el dedicar todo el Manual al análisis exclusivo de las psicopatologías, pues la CIE exclusivamente lo hace en un Título (Código F00-F99). No obstante, en lo relativo al contenido de las alteraciones la esencia de los Cuadros responde a criterios diagnósticos muy semejantes.

9 Vid. a modo de ejemplo RAMOS-QUIROGA, J.A.; BOSCH-MUNSÓ, R.; CASTELLS-CERVELLÓ, X.; NOGUEIRA-MORAIS, M.; GARCÍA-GIMÉNEZ, E. y CASAS-BRUGUÉ, M., «Trastorno por déficit de atención con hiperactividad en adultos: caracterización clínica y terapéutica», Revista de Neurología, Vol.42, №.10, 2006, pp.600-606. 
En lo que respecta a su etiología, el origen concreto de TDAH se desconoce si se atiende a la causa precisa del trastorno, pues aun caracterizándose por una base genética elevada ello no explicaría su manifestación al margen de otros factores externos -como podrían ser la historia personal o contexto de desarrollo-. Pese a ello, cabría dotar de un peso mayor al primer conjunto de factores, pues tal y como se ha defendido desde el King's College de Londres, incluso las consecuencias futuras dependerán de esta heredabilidad ${ }^{11}$.

Igualmente, si tuviera que estimarse algún tipo de predicción global, podría decirse que la tendencia general del TDAH es la disminución de sus tasas de prevalencia en edades posteriores, de manera que si bien algunos sujetos mantendrán el diagnóstico en la juventud, en menor medida lo harán en la edad adulta. En este sentido se podría admitir que, en ausencia de otras alteraciones, el pronóstico del cuadro por sí mismo sería favorable; es más, dicha favorabilidad será mayor cuanto menos sintomatología externalizante relacionada con la impulsividad presente el sujeto. A este respecto, si bien el peor pronóstico alude a la permanencia de los síntomas externalizantes, el más vinculado con la criminalidad y con la presencia de comorbilidad o presencia co-ocurrente de otras patologías será la impulsividad, siendo precisamente este aspecto el más reiterado en el DSM tras la acepción "clínicamente significativa". Concretamente, en palabras de Álvarez y Ollendick, «recientes investigaciones apoyan lo anterior, mostrando que sería la impulsividad y no la hiperactividad la predictora de posteriores conductas problemáticası ${ }^{12}$.

Por su parte, entre las mayores preocupaciones de los padres -que son quienes verdaderamente lidian a diario con los menores que presentan TDAH-, se encontraría el tipo de intervención que sería más adecuada para el tratamiento, pues la reticencia al empleo de fármacos -más aún cuando se trata de psicoestimulantes en menores-, suele ser elevada.

\footnotetext{
${ }^{10}$ WESTMORELAND, P.; GUNTER, T.; LOVELESS, P.; ALLEN, J.; SIELENI, B. and BLACK, D.W., «Attention Deficit Hyperactivity Disorder in Men and Women Newly Committed to Prison. Clinical Characteristics, Psychiatric Comorbidity, and Quality of Life»,, International Journal of Offender Therapy and Comparative Criminology, Vol.54, №.3, 2010, pp.361-377.

${ }^{11}$ Referencia web: http://www.kcl.ac.uk/iop/depts/mrc/research/adhdgen/adhdgeneticsgroup.aspx

12 ÁLVAREZ, H.K. and OLLENDICK, T.H., «Individual and Psychosocial Risk Factors», in Cecilia A. Essau, Conduct and Oppositional Defiant Disorders. Epidemiology, Risk Factors, and Treatment, New Jersey, Lawrence Erlbraum Associates, 2003, pp.107 y 108.
} 
Pero es más, siguiendo con la cuestión anterior, la reticencia de algunos progenitores podría llegar incluso a ser mayor al relacionar la ingesta de psicoestimulantes con la posible adicción futura, afirmación negada por diversos estudios de investigación cuando declaran que la intervención con este tipo de fármacos llegaría a prevenir el posible desarrollo de una adicción a sustancias en años posteriores actuando de este modo como factor protector en el desarrollo de un posterior trastorno relacionado con sustancias ${ }^{13}$. Pese a ello, cabría resaltar que la mejor intervención sería la integral, que complementaría, entre otras, la asistencia psicológica y educativa con la médica.

Retomando la cuestión planteada inicialmente, algunas investigaciones muestran el posible vínculo entre el individuo con diagnóstico de TDAH en la infancia y el riesgo de desarrollar conductas disruptivas y antisociales en años posteriores, lo cual podría llevar a la comisión de delitos. Claro está que si tal fuera la identificación respecto a la probabilidad de comisión de ilícitos, ello llevaría directamente a plantear la posible concurrencia de algunos de los beneficios penales previstos en el Código Penal. De esta forma, al entender que una merma suficiente tanto a nivel cognitivo y volitiva podría recaer sobre el sujeto con TDAH, ¿ por qué no admitir la exención o atenuación de la responsabilidad criminal? ¿Por qué no hablar de inimputabilidad o imputabilidad disminuida?

Evidentemente podría existir un riesgo de evolución negativa hacia comportamientos antisociales, principalmente por entender la sintomatología externalizante como factor de riesgo, pero ello será en circunstancias muy específicas. Es más, esta cuestión no cabría plantearla por el TDAH en sí mismo, sino por la presencia conjunta de otra psicopatología que pudiera concluir en dicho resultado, como podría ser el trastorno oposicionista-desafiante (TOD), el trastorno de conducta (TC), el trastorno relacionado con sustancias, o los trastornos de la personalidad a través, fundamentalmente, de las psicopatologías incluidas en el clúster B por su vinculación con la sintomatología externalizante, concretamente la impulsiva. En base a esto último, gran importancia tendría la comorbilidad clínica en la infancia como precursor de dichas alteraciones en años posteriores. A modo de ejemplo, autores como Speranza, RevahLevy, Cortese, Falissard, Pham-Scottez y Corcos, afirman que ello influiría en la presentación

\footnotetext{
13 MAYES, R.; BAgWeLL, C. and ERKULWATER, J., Medicating Children. ADHD and Pediatric Mental Health, Cambridge, Harvard University Press, 2009, pp.187 y ss.
} 
clínica del Trastorno Límite de Personalidad en adolescentes, asociándose a su vez con mayores tasas de trastornos disruptivos y de niveles de impulsividad. Así pues, respecto a ello, la co-ocurrencia del TDAH sería un factor precursor del desarrollo de otros trastornos del grupo $\mathrm{B}^{14}$.

Por último, si bien no se puede negar la afirmación del citado vínculo, en la actualidad la postura tiende a admitir una clara distinción entre el TDAH y las alteraciones comportamentales, tal y como deja ver la nueva estructuración de la APA en el DSM-5. Concretamente, la separación del TDAH del TOD y de TC -anteriormente conocidos como trastorno negativista-desafiante y disocial, respectivamente-, así como la inclusión del primero bajo el grupo de trastornos del neurodesarrollo previamente aludido, supone en cualquier caso la mayor consideración de aquél grupo de factores neurobiológicos con incidencia en los primeros años de vida. Un resumen esquemático se podría representar del siguiente modo:

Esquema 2. Representación de la reestructuración del DSM en base a la anterior denominación del "Trastorno por Déficit de Atención y Comportamiento Perturbador"15.

\footnotetext{
${ }^{14}$ SPERANZA, M.; REVAH-LEVY, A.; CORTESE, S.; FALISSARD, B.; PHAM-SCOTTEZ, A. and CORCOS, M., «ADHD in adolescents with borderline personality disorder», BMC Psychiatry, Vol.11, 2011, pp.158 y ss.

15 AGUILAR CÁRCELES, El Trastorno por Déficit de Atención e Hiperactividad (TDAH). Aspectos jurídicopenales, psicológicos y criminológicos, Madrid, Dykinson, 2014, p.264.
} 


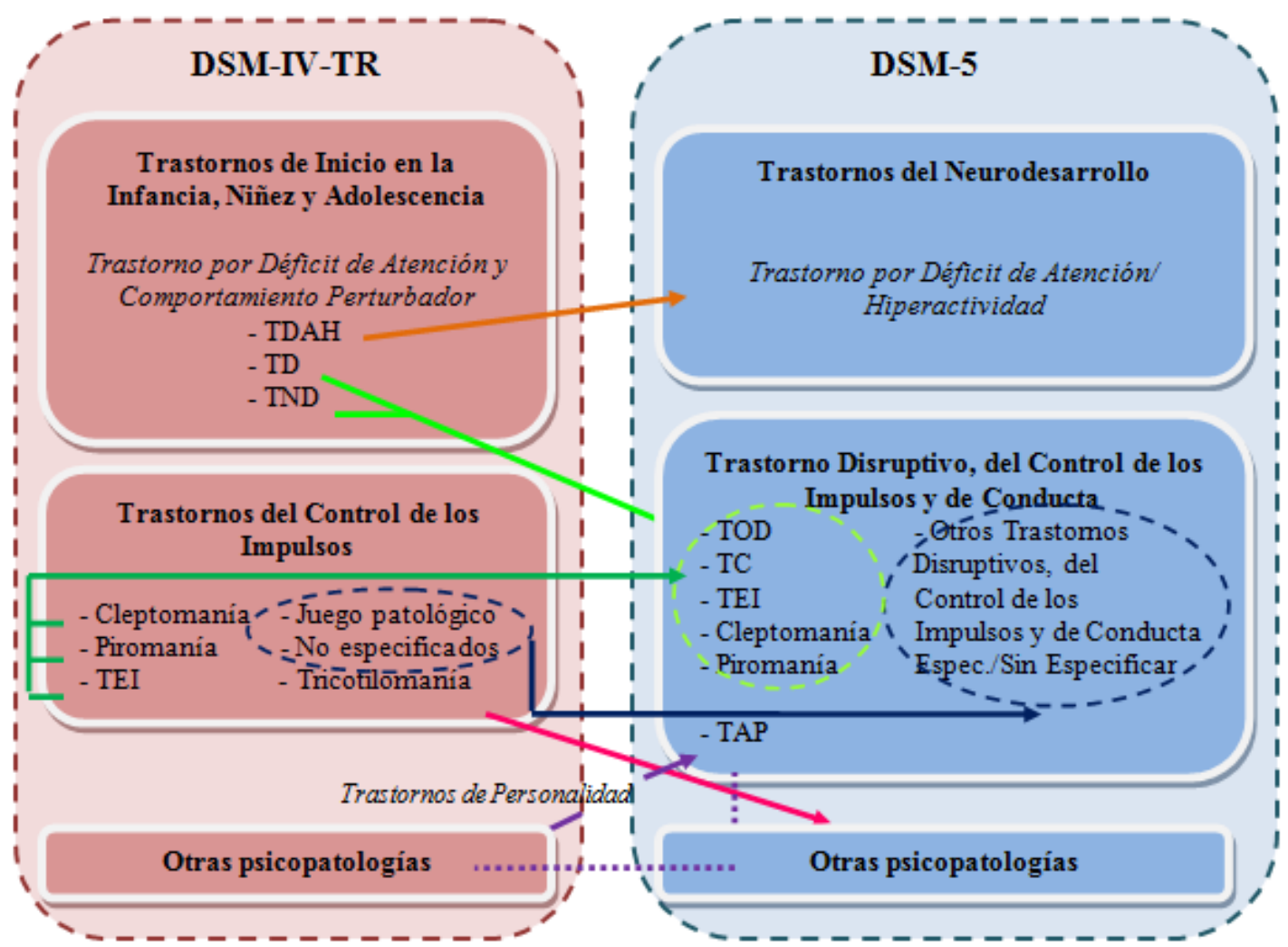

Como puede apreciarse en el esquema anterior, los cambios producidos con la quinta edición de la APA suponen modificaciones de gran calado -principalmente de tipo estructural-, siendo de los más evidentes la creación del título conjunto de "trastornos del neurodesarrollo", donde se albergan en la actualidad la mayoría de cuadros clínicos previamente ubicados en los "Trastornos de Inicio en la Infancia, Niñez y Adolescencia". Así pues, las alteraciones (funcionalmente significativas) del neurodesarrollo conceden especial relevancia a los aspectos biológicos no solo en la aparición del trastorno, sino también en lo relativo a su persistencia y/o cronificación posterior.

Todo lo referido hasta el momento concede una especial trascendencia al estudio del TDAH y a su vinculación con el comportamiento antisocial y posterior carrera criminal, sobre todo a los efectos de poder contemplar dicha patología como beneficiaria de lo recogido en el apartado primero del artículo 20 CP. Ahora bien, ¿realmente la severidad de dicha patología en este ámbito como para considerar al sujeto que la presenta como "inimputable" a los ojos de 
los Tribunales españoles? ¿Qué sucedería con otras alteraciones con mayor peso en cuanto a su afectación intelectiva y volitiva pero que no vienen siendo contempladas por la doctrina penal? Estas y otras cuestiones se debatirán seguidamente.

\section{La cuestión de inimputabilidad sobre el TDAH en su comparativa con las} psicopatológicas comúnmente descritas por la doctrina penal como "permanentes"

La cuestión que se plantea en el presente trabajo sobre la probabilidad de otorgar algún beneficio penal a quien presenta un diagnóstico de TDAH, implica la necesidad de estudiar la redacción del artículo 20 del Código Penal en su primer apartado -así como el art. 21.1 CP por extensión y referencia expresa a aquél $-{ }^{16}$, donde del tenor literal del precepto podría derivarse la exención de responsabilidad criminal -o atenuación-, siempre que motivada y justificadamente así se considere.

Es por esta razón por lo que entiendo pertinente aludir, si bien de una manera más bien breve y concisa, al tratamiento otorgado a otras patologías mentales y efectuar un análisis respecto a las mismas, de manera que a partir de su valoración y comparación con el TDAH pueda apreciarse la dificultad en la concesión de "privilegios penales" a este último trastorno.

En su confrontación con el tratamiento jurisprudencial que nivel nacional se ha otorgado a otras patologías, se elabora un análisis acerca de la relevancia jurídico-penal de algunos de los trastornos mentales más controvertidos. En base a ello, la cuestión de la inimputabilidad conforme al artículo $20 \mathrm{CP}$ en su primer apartado se analizará conforme al planteamiento de la probabilidad de inclusión de las patologías en él reflejadas y el porqué no del TDAH.

\footnotetext{
${ }^{16}$ Afirma el artículo 21.1 CP que se aplicará la atenuación a "Ias causas expresadas en el capítulo anterior, cuando no concurrieren todos los requisitos necesarios para eximir de responsabilidad en los respectivos casos".
} 
Tal y como expresa el apartado primero del art. $20 \mathrm{CP}$ "el que al tiempo de cometer la infracción penal, a causa de cualquier anomalía o alteración psíquica, no pueda comprender la ilicitud del hecho o actuar conforme a esa comprensión". A lo que añade "el trastorno mental transitorio no eximirá de pena cuando hubiese sido provocado por el sujeto con el propósito de cometer el delito o hubiera previsto o debido prever su comisión".

Atendiendo al concepto de imputabilidad como el conjunto mínimo de facultades necesarias en cuanto a la comprensión y voluntad del individuo para la comisión de un delito, pudiera decirse que tanto el componente cognoscitivo como el volitivo constituirán la base para declarar a un sujeto como imputable, pues existiendo una alteración en alguno de los aspectos señalados -y siempre que su relación sea suficientemente grave ${ }^{17}$ y directa con el hecho ilícito cometido-, podrá entenderse la aplicación de la eximente o atenuante en razón de dicho apartado. Como puede observarse, el concepto de imputabilidad no viene referencia en el Código Penal más que en su sentido negativo por referencia expresa a lo comprensible por inimputabilidad.

Igualmente, la apreciación de esta circunstancia se basa en un doble requisito o criterio mixto de identificación, aspecto al que alude reiteradamente la jurisprudencia ${ }^{18}$ y la doctrina penal. Así por ejemplo, Cobo del Rosal y Vives Antón afirman la necesaria presencia de un "conjunto de requisitos psicobiológicos exigidos por la Legislación Penal vigente, que expresan que la persona tenía la capacidad de valorar y comprender la ilicitud del hecho realizado por ella y de actuar en los términos requeridos por el Ordenamiento Jurídico" ${ }^{19}$.

\footnotetext{
${ }^{17}$ Respecto a la consideración de presentarse una alteración "suficientemente grave" capaz de anular las capacidades referidas, lo cierto es que desde el ámbito penal este vocablo podría asemejarse a lo que comúnmente viene reconocido en los Manuales Diagnóstico Internacionales como "significación clínica" o impacto de la alteración/psicopatología en el individuo. Se trata de un inciso que considero conveniente resaltar por cuanto no sería posible apreciar severidad sintomática por el Tribunal en la contemplación de la eximente si el cuadro clínico, ya de por sí, no altera de manera significativa o funcional la vida del sujeto. Pese a ello, excepcionalmente podrá apreciarse un individuo en fase residual -en cuanto a la sintomatología de la patología se refiere-, que padezca en un momento concreto una merma severa y suficiente que afecta a la capacidad cognitiva y/o volitiva, lo que no quiere decir que previamente no haya habido significación clínica en lo que a la enfermedad mental se refiere.

${ }^{18}$ Vid. a modo de ejemplo la Sentencia del Tribunal Supremo 80/2015, de 6 de febrero [RJ 2015\515] y la Sentencia del Tribunal Supremo 158/2015, de 17 de marzo [RJ 2015\991]

${ }^{19}$ COBo Del ROSAL, M. y VIVES ANTÓN, T. S., Derecho Penal. Parte General (4 ${ }^{\text {a }}$ Edición), Valencia, Tirant lo Blanch, 1999, pp.575 y ss.
} 
En base a lo anterior, conforme a lo estipulado en el precepto, parece obvio que la generalidad a la que alude el 20.1 CP podría hacer pensar sobre la inclusión de cualquier psicopatología, a lo que se añade la disyuntiva cuando se habla de afectación ${ }^{20}$. De esta forma, no se hace necesaria la concurrencia de los dos requisitos, cognitivo y volitiva, sino que uno de ellos basta para la apreciación del tipo.

En relación a la primera de las afirmaciones, evidentemente se trata de una fórmula de enorme amplitud y flexibilidad por cuanto, aparentemente, cualquier alteración o patología psiquiátrica sería causa capaz de producir los requisitos exigibles para la apreciación del artículo 20.1 CP. Ahora bien, ¿realmente tendría cabida cualquier patología en dicho supuesto? ¿Podría entonces comprenderse el TDAH cuya sintomatología externalizante, como se ha comentado, podría vincularse con psicopatologías más severas?

La doctrina mayoritaria se ha decantado por albergar bajo dicho supuesto las consideradas como anomalías mentales "permanentes", las cuales se encuadrarían dentro de alguno de los siguientes grupos ${ }^{21}$ : a) psicosis de tipo exógeno o endógeno (esquizofrenia, paranoia, psicosis maníaco-depresiva, etc.) ${ }^{22}$; b) neurosis (entendidas como simples reacciones vivenciales anómalas, y que incluso pudieran manifestarse en forma de angustia, depresión, o mecanismos defensivos); c) oligofrenias ${ }^{23}$; y d) psicopatías. A todo ello se une el trastorno mental transitorio (TMT), así como la posible cabida de las demencias, trastorno bipolar,

\footnotetext{
${ }^{20}$ Disyuntiva de la que se hace crítica en la Sentencia de la Audiencia Provincial de Murcia 47/2009, de 21 de septiembre [JUR 2010\255090], pues se entiende que "un trastorno patológico de la voluntad no se produce con independencia y sin ninguna afectación de las funciones superiores o cognitivas".

21 ORTS BERNEGUER, E. y GONZÁLEZ CUSSAC, J. L., Compendio de Derecho Penal. Parte General. 2a Edición actualizada conforma a la LO 5/2010, Valencia, Tirant lo Blanch, 2010, p.188; y MUÑOZ CONDE, F. y GARCíA ARÁN, M., Derecho Penal. Parte General (8a Edición), Valencia, Tirant lo Blanch, 2010, cit., pp.370 y 371.

${ }^{22}$ Según Mir Puig, en la caracterización de las Psicosis habría que tener en cuenta tanto la base somática del paciente como la transformación no transitoria de las leyes psíquicas, resultando en una alteración cualitativa a dicho nivel. Concretamente, refiere el autor que en las Psicosis endógenas si se han demostrado con mayor rigor las alteraciones bioquímicas existentes, no siendo así en el caso de las exógenas. Vid. más ampliamente en MIR PUIG, S., Derecho Penal. Parte General (9ª Edición), Barcelona, Editorial Reppertor, 2011, pp.576 y ss.

${ }^{23}$ Conforme a su definición y delimitación a nivel jurisprudencial, indica la Sentencia de la Audiencia Provincial de Alicante 829/2012, de 20 de noviembre [ARP 2013\84] que «la Oligofrenia, Retraso Mental o también denominada Debilidad Mental constituye -según se describe en la doctrina científica- un trastorno permanente del individuo producido en los momentos iniciales de su maduración psicosomática debido a factores diversos (congénitos o adquiridos) que se traduce en un déficit de todas o algunas estructuras orgánicas y por una perturbación de la vida instintiva, volitiva y afectiva, determinando el desarrollo de la personalidad en su globalidadı. Vid. Sentencia de la Audiencia Provincial de Alicante 829/2012, de 20 de noviembre [ARP 2013\84].
} 
trastornos del control de los impulsos (TCI), trastornos sexuales ${ }^{24}$, y epilepsias ${ }^{25}$; entre otros, aunque, como se acaba de mencionar, comúnmente constituirán aquel precepto los cuatro grupos inicialmente mencionados y, en su caso, el TMT para el segundo de los supuestos (segundo párrafo) del primer precepto del artículo 20 CP.

Se trata de campos caracteriológicos que, para responder al tipo, tendrán que estar a lo dispuesto por la Sentencia del Tribunal Supremo 120/2014, de 26 de febrero [RJ 2014\928] cuando afirma que la eximente completa «solo será posible cuando se haya acreditado que el sujeto padece una anomalía o alteración psíquica que le impida comprender la ilicitud de su conducta o actuar conforme a esa comprensión, y que tal cosa solo puede tener lugar en ocasiones excepcionales, debiendo ser acreditado debidamente ${ }^{26}$. Así pues, no basta la mera calificación clínica, sino que la consecuencia vendrá a determinarse en relación al acto delictivo ${ }^{27}$, afirmación también puesta de relieve en la Sentencia del Tribunal Supremo 158/2015, de 17 de marzo [RJ 2015\991], así como en la Sentencia del Tribunal Supremo 80/2015, de 6 de febrero [RJ 2015\515] en relación a la doble exigencia de una causa biopatológica.

Claro está que la presencia de un diagnóstico no derivará inexcusablemente en la contemplación de la inimputabilidad, muy a pesar de la cláusula tan genérica y abierta que,

\footnotetext{
${ }^{24}$ Vid. más ampliamente en FONSECA MORALES, G.M., La anomalía o alteración psíquica como eximente o atenuante de la responsabilidad criminal, Madrid, Dykinson, 2007, pp.229 y ss.

${ }^{25}$ Se define la Epilepsia como una enfermedad neurológica que podría tener la misma respuesta penal para la consideración de la imputabilidad que en el caso de las patologías mentales; concretamente, por su inclusión como anomalía o alteración psíquica o, mejor dicho, por las afecciones que a dicho nivel pudiera producir. Dada su vinculación con la esquizofrenia, y aun no siendo catalogada como un trastorno mental ni por la CIE ni por el DSM pero sí reflejada como posible sintomatología, la epilepsia a efectos de la imputabilidad conllevaría importantes connotaciones. Específicamente, y haciendo un breve inciso sobre la relación anterior, estudios recientes refieren la relación bidireccional entre la esquizofrenia y la epilepsia, confirmando que quienes presentan esta última tienen casi ocho veces más posibilidades de desarrollar esquizofrenia, mientras que en los individuos con esquizofrenia las probabilidades de desarrollar epilepsia se multiplicarían por seis. Vid. más ampliamente en International League Against Epilepsy (ILAE). Recurso electrónico disponible en: http://www.ilae.org

${ }^{26}$ Vid. en la misma línea la Sentencia del Tribunal Supremo 11014/2013, de 12 de diciembre [RJ 2014\329]

27 CLIMENT DURÁN, C., Código Penal. Jurisprudencia Sistematizada (4ạ Edición), Valencia: Tirant lo Blanch, 2011, pp.85 y ss.
} 
empleada en el Código Penal, pudiera hacer suponer lo contrario -aspecto que todavía se enfatiza en mayor medida cuando se aprecia que la misma redacción del Código hace alusión a la disyuntiva "comprender la ilicitud del hecho o actuar conforme a esa comprensión"-. Es por ello que la doctrina penal viene delimitando el grupo de patologías que pudieran quedar adheridas a la contemplación de aquella circunstancia, que tampoco lo serán en todas las situaciones, pues en última instancia será el Tribunal sentenciador el que deba realizar el juicio sobre la culpabilidad de acuerdo a la afectación del sujeto de la capacidad de comprender la antijuricidad de la acción y de autodeterminar la conducta.

Precisamente en relación a aquél grupo que responde a la denominación de "anomalía o alteración psíquica permanente", y en razón del modelo mixto empleado por el legislador español, López Barja de Quiroga et al. refieren expresamente que dicha fórmula psiquiátricapsicológica adoptada en el artículo 20.1 del Código Penal debe basarse expresamente en la gravedad de la alteración y en su proyección sobre los hechos. En el mismo sentido, indican que la valoración del plano normativo-valorativo de la patología conducente a la abolición total o casi absoluta de la capacidad cognitiva y volitiva podrá suponer la exclusión del dolo como capacidad de saber lo que se hace y de hacer lo que se quiere ${ }^{28}$.

En esta línea, la vinculación del efecto de la alteración con la capacidad de comprender y actuar del sujeto bajo una perspectiva mixta resulta en un tipo de relación causal e inequívoca para la apreciación de la eximente completa. Concretamente, indican Carrasco Gómez y Maza Martín que desde el punto de vista psicobiológico la aplicación del artículo 20 del Código Penal responderá a una cuádruple comprobación ${ }^{29}$ :

i) Criterio cualitativo o análisis de la naturaleza de la perturbación, donde se valoran tanto la capacidad intelectiva como la de autodeterminación a nivel biopsicológico.

\footnotetext{
28 LÓPEZ BARJA DE QUIROGA, J. (Dir.), Código Penal con jurisprudencia sistematizada (5a Edición), Valencia: Tirant lo Blanch, 2014, pp.85 y ss.

${ }^{29}$ CARRASO GÓMEZ, J. J. y MAZA MARTíN, J. M., Manual de Psiquiatría Legal y Forense, Madrid, La LeyActualidad, 2010, pp.5-14.
} 
ii) Criterio cuantitativo o valoración de la intensidad y grado de la perturbación, de manera que la severidad de la afectación pudiera explicar en mayor o menor medida la pérdida o merma de las facultades ya referidas. De este modo, la afectación absoluta del estado psíquico del individuo -de manera que el sujeto se encuentre privado tanto de su capacidad de comprensión como de volición-, actuaría a favor de la inimputabilidad.

iii) Criterio cronológico o de duración/ permanencia del trastorno, mediante el cual se valora la coincidencia entre el estado del sujeto y la materialización de los hechos imputados.

iv) Criterio causal entre el trastorno psicopatológico y el hecho delictivo, donde el trastorno o anomalía sufrida en el instante señalado fuera suficiente como para explicar la comisión del ilícito.

Una extrapolación de lo anterior al TDAH requeriría comprenderlo con capacidad de anular o privar las facultades referidas o bien, mermarlas en modo suficiente, siendo su presencia coincidente con el momento de la comisión del ilícito y capaz de explicar casualmente dicho modo de actuar. De esta forma, la inatención, hiperactividad, e impulsividad, como descriptores del Trastorno, y en aras a apreciar alguna de las circunstancias modificativas de la responsabilidad criminal (exención o atenuación), deberán presentarse en los términos descritos.

Por tanto, cabría decir que en exclusividad se ciñe el Código Penal a limitar las causas de inimputabilidad (criterio negativo de alusión a la imputabilidad), que al igual que la imputabilidad se constituiría como un constructo jurídico de base psicológica establecido sobre el conjunto de capacidades mínimas que deberá reunir el sujeto autor de un delito para ser considerado culpable. Concretamente, indica Guisbert-Calabuig que los aspectos psiquiátricoforenses de la imputabilidad serían: 1) el estado de madurez mínimo, fisiológico y psíquico; 2) 
la existencia de plena conciencia de los actos que se realizan; 3) la capacidad de voluntariedad o facultad volitiva; y 4) la capacidad de libertad de acción o facultades cognitivas ${ }^{30}$.

Con todo ello, la cuestión sobre el análisis de la incongruencia a nivel legislativo y jurisprudencial abre un amplio espectro de interrogantes, no solamente en cuanto al TDAH, sino también respecto a otras alteraciones psíquicas que pudiendo tener su foco de interés en la afectación de la cognición o volición no hayan venido siendo contempladas (p.ej. trastornos del control de los impulsos), o bien que de hacerlo, lo sean en modo distinto. Igualmente, podría suceder que casos muy similares sean tratados de manera distinta por los Tribunales por apreciar en uno de ello una mayor rebaja penal -pero en ello deriva precisamente el arbitrio del Juez-. De cualquier forma, será precisamente la práctica judicial la que determine los supuestos con cabida en este apartado.

Dejando al margen lo anterior por la extensión que ello supondría y la que se dispone, se ciñe el trabajo en realizar se hace un repaso de aquellas consideradas más relevantes a nivel penal desde el prisma de la comparativa y vinculación del TDAH con las alteraciones psíquicas permanentes, poniendo el mayor énfasis en aquéllas alteraciones relativas a las psicosis y psicopatías.

2.1. Psicosis: especial referencia al TDAH y a la Esquizofrenia (Trastornos del Espectro Esquizofrénico)

Autores como Kindt refieren que el término "psicosis" fue empleado por primera vez por Ernst Freiherr von Feuchtersleben en el año 1845 para definir de manera amplia y genérica a cualquier tipo de alteración psíquica ${ }^{31}$, afirmación no respetada a día de hoy por comprender aquella acepción como un grupo de alteraciones específicas con determinadas particularidades.

\footnotetext{
${ }^{30}$ GISBERT CALABUIG, J.A., Medicina Legal y Toxicología, Barcelona, Masson, 2004, pp.331 y ss.

${ }^{31}$ KINDT, H., «Zur Entstehung und Entwicklung des Psychose-Begriffes», Fortsch. Neurol. Psychiat., 42, 1974, pp.453-464.
} 
En este contexto, Geekie y Read señala que «aunque el concepto de locura apenas se utiliza en el marco de la psicopatología y la psiquiatría modernas, suele identificarse con otros términos más científicos como la psicosis o la esquizofrenia», a lo que añaden «fenómenos estos que tienden a asociarse a manifestaciones que pueden presuponer cierto grado de ruptura con la realidad, básicamente a través de alteraciones cognitivas diversas tales como las alucinaciones, las ideas delirantes o las alteraciones formales del pensamiento, y alteraciones graves del comportamiento desorganizado» ${ }^{32}$.

Siguiendo a López Barja de Quiroga, las modalidades de la psicosis responderían a la distinción entre psicosis de tipo endógeno y exógeno, pues mientras en el primer grupo se situarían aquellas provenientes de causas internas del sujeto y distinguirían entre las psicosis de tipo afectivo (melancólica, maníaco-depresiva) y de tipo delirante (esquizofrenia, paranoia, parafrenia), el segundo grupo englobaría aquellas otras psicosis cuyo origen emana de una causa externa y que también produciría una modificación sustancial o alteración mental en el sujeto, bien sean de tipo tóxico (producidas por toxinas en el interior del organismo, toxifrenias como consecuencia de una drogadicción) como orgánico (lesiones cerebrales traumáticas, sinfílicas o por involución fisiológica en la vejez) ${ }^{33}$.

En cualquier caso, el enfermo psicótico presenta un estado mental capaz de modificar, perturbar o anular suficientemente la capacidad intelectiva y volitiva, pudiendo definirse como una alteración de carácter crónico y permanente muy a pesar de los períodos de reposo que pudiera presentar el sujeto en cuestión. Por tanto, podría decirse que las psicosis, y la esquizofrenia en particular, patologías mentales severas que ocasionan una gran perturbación en las relaciones sociales, familiares y labores de las personas que la sufren, que se inicia generalmente en la adolescencia, que tiene tendencia a evolucionar hacia la cronicidad y para la cual, no existe más mejora que la producida por su remisión sintomática con el uso de antipsicóticos.

\footnotetext{
${ }^{32}$ GEEKIE, J. y READ, J., El sentido de la locura, Barcelona: Herder Editorial, 2012.

33 LÓPEZ BARJA DE QUIROGA, J. (Dir.), Código Penal con jurisprudencia sistematizada (5a Edición), Valencia: Tirant lo Blanch, 2014, pp.85 y ss.
} 
En lo que atañe a su comprensión, desde el ámbito internacional se ha producido una importante modificación en cuanto a la catalogación de este tipo de alteraciones, pues si bien años atrás la APA y la $\mathrm{OMS}^{34}$ distinguían un conjunto de tipos psicóticos, desde el año 2013 el DSM-5 define la existe de un continuum de alteraciones relacionadas con el espectro esquizofrénico. Dicho ello, la primera diferencia que se observa respecto a este conjunto de trastornos alude a la propia denominación que en este momento emplea la APA, pues mientras en años precedentes eran conocidos como "Esquizofrenia y otros trastornos psicóticos", en la actualidad la denominación otorgada responde a los "trastornos del espectro esquizofrénico y otros trastornos psicóticos" (conocidos los primeros por las siglas TEE) ${ }^{35}$. En esta línea, actualmente su denominación bajo dicho título permite observar que se trata de un conjunto de cuadros con una indiscutible relación entre ellos, muy a pesar de sus diferencias sintomáticas en cuanto a tipos (p.ej. catatónico), curso, pronóstico y evolución se refiere ${ }^{36}$, lo cual incidirá en el análisis de la cuestión de imputabilidad-inimputabilidad. Unido a ello, dentro del ámbito que aquí compete, los períodos fluctuantes caracterizadores de dicha patología devienen en la incertidumbre cuando se trata de valorar la causalidad respecto del ilícito cometido.

Sea como fuere, este trastorno se caracteriza por distorsiones de la percepción, pensamiento y emociones, estas últimas en forma de embotamiento e incoherentes, del mismo modo que el trastorno compromete las funciones esenciales relacionadas con la vivencia de su individualidad, singularidad y dominio de sí mismo. El enfermo cree que

\footnotetext{
${ }^{34}$ Siguiendo la Organización Mundial de la Salud en su Manual de 1992 (última revisión en 2010), la CIE diferencia en su Código F20-29 ("Esquizofrenia, trastorno esquizotípico y trastornos de ideas delirantes"), la esquizofrenia de tipo paranoide, hebrefrénica, catatónica, indiferenciada, residual o simple, entre otras.

${ }^{35}$ En este contexto, como no podía ser menos si se analiza la actual denominación otorgada al Capítulo que alberga estos Trastornos, el hablar de "espectro" refleja la consideración de la APA de la continuidad sintomática de los diferentes subtipos que previamente diferenciaba y trataba de una manera independiente (Paranoide, Desorganizada, Catatónica, Indiferenciada y Residual), lo que vuelve a justificarse por la marcada importancia que concede a la continuidad de las psicopatologías en esta Quinta Edición de 2013. Por tanto, se procede en idéntico sentido que se hizo con los TEA, homologando la denominación de "espectro" a "continuum de severidad sintomática".

${ }^{36}$ Se distingue fundamentalmente la sintomatología positiva por implicar una hiperactivación de las funciones normales del organismo (delirios, alucinaciones, angustia, excitabilidad) de la sintomatología negativa (alogia o empobrecimiento del pensamiento, anhedonia-insociabilidad, pérdida de afectividad, abulia o apatía, etc.).
} 
sus pensamientos, sentimientos y actos más íntimos son conocidos o compartidos por otros y pueden presentarse ideas delirantes en torno a la existencia de fuerzas naturales o sobrenaturales capaces de influir en los actos y pensamientos del individuo, sintiéndose en ocasiones el centro de todo lo que sucede.

El sujeto con esquizofrenia podrá experimentar comportamientos inquietud corporal y agitación (sintomatología positiva), pero la etiología de los mismos no responde a una alteración común, sino que dichos síntomas tendrán que explicarse dentro de la enfermedad psicótica. A su vez, resulta crucial distinguir cual es la fase en la que se encuentra el sujeto en el momento de cometer la acción ilícita, siendo el contenido y la afectación de las ideas delirantes y alucinaciones fundamental, y sustentador, de cara a la valoración y aplicación del artículo $20.1 \mathrm{CP}$

Aun no siendo comunes de hallar de manera conjunta por entender la ausencia de alucinaciones o de ideas delirantes en el TDAH, podrían encontrarse características similares cuando se hace referencia tanto a la probabilidad de realizar conductas autolesivas, como a la escasa conciencia del entorno que pudieran mostrar ${ }^{37}$. En el caso del TDAH, la actividad motora es incesante, irregular, y menos predecible que en niños psicóticos, siendo las reacciones emocionales significativas, de no mucha duración y manifestadas, en gran parte de las ocasiones, en rabietas. Igualmente, el curso entre una y otro psicopatología es bien distinto cuando se valoran de manera separada, de modo que ante la posible mejora del TDAH, los psicóticos normalmente tienden a empeorar.

Tanto el DSM-IV como la CIE-10 definen las psicosis como trastornos excluyentes del TDAH, aun cuando a nivel atencional aquéllos pudieran presentar distracción por las propias alucinaciones o fragmentación en los procesos cognitivos, al igual que las confusiones pudieran también darse en base a la impulsividad por la irritabilidad paranoide y agitación nocturna, o en la hiperactividad por la agitación y cambios bruscos en la actividad, también son evidentes las diferencias. Por su parte, podrán hallarse similitudes entre la psicosis y el TDAH cuando se

37 POPPER, C.W.; GAMMON, G.D.; WEST, S.A. and BAILEY, C.E.; «Disorders Usually First Diagnosed in Infancy, Childhood and Adolescence»), in Robert E. Hales and Stuart C. Yudofsky, Textbook of Clinical Psychiatry (4 ${ }^{\text {th }}$ Edition), Washington, The American Psychiatry Publishing, 2003, pp.833 y ss. 
trata de valorar otros tipos de conductas (p.ej. autolesiones en casos extremos), aunque las diferencias sigan estando presentes. Tal es el caso de la afectación atencional, acompañándose en muchas ocasiones en la psicosis de inhibición motórica, aunque dependiendo de la tipología y condicionantes podrá presenciarse la agitación o hiperactividad previamente indicada. No obstante, es tan pronunciada la distinción entre uno y otro trastorno que el propio DSM-5 afirma que «el TDAH no será objeto de diagnóstico si los síntomas de inatención e hiperactividad ocurren exclusivamente en el curso de un trastorno psicótico» ${ }^{38}$.

La etiología de los trastornos no responde a una alteración común, de manera que cuando dichos síntomas tiendan a explicarse dentro de la enfermedad psicótica resultará crucial distinguir cual es la fase en la que se encontraba el individuo en el momento de cometer la acción ilícita, siendo el contenido y la afectación de las ideas delirantes y alucinaciones fundamental, y sustentador, de cara a la valoración y aplicación del artículo 20.1 CP. De esta forma, serían síntomas más propios de los TEE la desorientación, alucinaciones, delirios, pobreza del pensamiento, o alteración de la realidad, entre otros, mientras la ausencia de alucinaciones e ideas delirantes es un hecho constatable en el individuo con TDAH. No obstante, sí que podrían hallarse similitudes cuando se trata de valorar otros tipos de conductas (p.ej. autolesiones en casos extremos)

A este respecto, resulta curioso el planteamiento de la Sentencia de la Audiencia Provincial de Tarragona 361/2013 [JUR 2013\344657] cuando cuestiona e incide en la posibilidad de confusión de los síntomas del TDAH con los de la esquizofrenia, no siendo clara la repuesta del perito. Así, en su relación con el TDAH, el sujeto con esquizofrenia podrá experimentar comportamientos similares pero el diagnóstico diferencial entre ambos deja patente sus indudables diferencias.

En cualquier caso, habría que decir que recientes investigaciones apoyan núcleos biológicos compartidos, como sería la presencia de determinados correlatos biológicos

\footnotetext{
${ }^{38}$ AMERICAN PSYCHIATRIC ASSOCIATION (APA), Diagnostic and Statistical Manual of Mental Disorders, Fifth Edition (DSM-5)... cit., p.65.
} 
comunes - aunque existen muchas más diferencias que similitudes entre dichos cuadros ${ }^{39}$, así como su existencia comórbida con la depresión, trastorno bipolar y autismo ${ }^{40}$. Estos hallazgos son considerados de enorme relevancia, más aún conociendo que los déficits cognitivos en el desarrollo como signo prodrómico o factor de riesgo en la evolución hacia una psicosis, al igual que sucede con la escasa concentración en el juego, tardanza en la adquisición de lenguaje o la presencia de un $\mathrm{Cl}$ bajo $^{41}$.

Dejando al margen lo anterior, la posibilidad de aplicación del art. 20.6 CP eximiría de responsabilidad al que actuara por miedo insuperable, donde podría tener cabida el contenido alucinatorio e ideación delirante amenazadora para el sujeto. Según Quintero Olivares, un individuo con esquizofrenia paranoide en fase psicótica aguda podría comprenderse dentro de este supuesto ${ }^{42}$.

Del mismo modo, continúa el autor aludiendo a la nula posibilidad de aplicación del artículo 20.3, pues entiende que las alteraciones de la percepción con alteración de la conciencia no estarían presentes desde el nacimiento, sino en períodos más tardíos. Respecto a ello, entiendo que ciertamente es complicado apreciar tales disfunciones desde las primeras etapas si se refiere a su observancia desde el momento del nacimiento; ahora bien, ello no excluiría la posibilidad de apreciar este tipo de sintomatología desde edades tempranas. En este sentido, conocida la carga genética presente en tal patología, lo cierto es que la susceptibilidad a su manifestación estaría presente sin llegar a ser explícita hasta períodos de tiempo más tardíos.

39 WILLIAM, N.M.; ZAHARAIEVA, I.; MARTIN, A.; LANGLEY, K.; MANTRIPRAGADA, K.; FOSSDAL, R.; STEFANSSON, H.; MAGNUSSON, P.; GUDMUNDSSON, O.O.; GUSTAFSSON, O.; HOMANS, P.; OEWN, M.J.; O'DONOVAN, M. and THAPAR, A., «Rare chromosomal deletions and duplications in attention-deficit hyperactivity disorder: a genome-wide analysis», The Lancet, Vol.376, №.9750, 2010, pp.1401-1408. Recurso electrónico disponible en la siguiente dirección: http://www.cardiff.ac.uk/news/articles/adhdsgenetic-link-5492.html

${ }^{40}$ CROSS-DISORDER GROUP OF THE PSYCHIATRIC GENOMICS CONSORTIUM, «Genetic relationship between five psychiatric disorders estimated from genome-wide SNPs $»$, Nature Genetics, Vol.45, 2013, pp.984-994.

${ }^{41}$ TIZON, J. L. et al., «Factores de riesgo para padecer trastornos psicóticos: ¿Es posible realizar una detección preventiva?», Clínica y Salud, vol.19, n.1, 2008, pp. 27-58.

${ }^{42}$ QUINTERO OLIVARES, G., Locos y culpables, Navarra: Aranzadi, 1999, pp.55 y ss. 
El criterio de aplicación de la eximente del artículo 20.3 CP es muy restrictivo y de difícil apreciación, albergando a individuos en una situación intelectual y social incluso peor que un enfermo mental ${ }^{43}$. De nuevo, la aplicación de la eximente no atañe en exclusividad a supuestos de patologías mentales diagnosticadas, sino que habrá de estar a la sintomatología manifestada en un preciso instante.

Interesante sería en el caso de la esquizofrenia destacar la amplia posibilidad de catalogación del sujeto en supuestos de inimputabilidad en base al grado de afectación con que aquellas facultades hubieran podido interferir causando la conducta imputada. Así pues, tomando como referencia la Sentencia del Tribunal Supremo de 1998, se considera la posibilidad de aplicación tanto del artículo $20.1 \mathrm{CP}, 21.1 \mathrm{CP}$, y $21.6 \mathrm{CP}$ en la esquizofrenia dependiendo de la sintomatología concurrente en el individuo en aquel momento de la comisión de ilícito, que no del inciso tercero del artículo 20 CP. De manera más específica, y bajo la presencia de la sintomatología de la patología apoyada en un posible brote psicótico, se deducen las siguientes consideraciones ${ }^{44}$ :

i) La eximente completa tendrá cabida cuando el sujeto hubiera actuado bajo los efectos del brote psicótico (art. 20.1 CP). Pese a ello, la Sentencia del Tribunal Supremo 1192/2011, de 16 de noviembre [RJ 2012\1532] pone de relieve como el sujeto esquizofrénico no siempre ha de ser considerado un sujeto totalmente inimputable, debiendo de valorarse ad hoc las siguientes circunstancias: a) intensidad de la influencia de la alteración sobre el psiquismo del sujeto; b) la proximidad entre el momento ejecutivo y el brote; c) relación causal entre la psicosis y el comportamiento -estimado inexistente cuando aquélla es residual y transcurre sin mermar la capacidad de autodeterminación-; d) el grado de deterioro intelectivo; e) la tipología delictiva cometida; y f) la existencia de otros factores -entiendo criminógenos-, capaces de incrementar la intensidad de la patología psíquica.

\footnotetext{
${ }^{43}$ Ibídem, p.117.

${ }^{44}$ Recurso electrónico disponible en: http://vlex.es/tags/imputabilidad-e-inimputabilidad-esquizofrenia313080
} 
ii) La eximente incompleta será de aplicación cuando, aún en presencia de la enfermedad el sujeto no hubiese actuado bajo aquel brote (art. 21.1 CP). Con ello se quiere decir que, reconociendo la incapacidad que podría provocar la esquizofrenia, solo en casos excepcionales será de aplicación lo previsto en el artículo 20.1 CP.

iii) La atenuante analógica podrá considerarse cuando, sin existencia de brote y $\sin \tan$ marcada disfuncionalidad, el individuo pudiera actuar como consecuencia del residuo patológico de la enfermedad (art. 21.6 CP).

Ahora bien, muy importante en la consideración de todo ello sería la evaluación individual, así como la valoración del tratamiento farmacológico -y los efectos del mismo-, en el momento en que se cometió la acción imputada. Nuevamente, la gravedad de la psicopatología se valora de cara a la intensidad necesaria para la inimputabilidad, apreciándose así el dinamismo que caracteriza a la propia esquizofrenia.

Por último, y dada su vinculación con la patología citada aun no siendo catalogada como un trastorno mental ni por la CIE ni por el DSM pero sí reflejada como posible sintomatología, la epilepsia a efectos de la imputabilidad conllevaría importantes connotaciones. De manera específica, estudios recientes refieren la relación bidireccional entre la esquizofrenia y la epilepsia, confirmando que quienes presentan esta última tienen casi ocho veces más posibilidades de desarrollar esquizofrenia, mientras que en los individuos con esquizofrenia las probabilidades de desarrollar epilepsia se multiplicarían por seis ${ }^{45}$.

Se define la epilepsia como una enfermedad neurológica que podría tener la misma respuesta penal para la consideración de la imputabilidad que en el caso de las patologías mentales; es decir, su inclusión como anomalía o alteración psíquica emana de las propias afecciones cognitivo-volitivas.

\footnotetext{
45 Vid. International League Against Epilepsy (ILAE). Recurso electronico disponible en:
} http://www.ilae.org 
En este sentido, la inimputabilidad del sujeto resulta evidente en supuestos de ataques de epilepsia (crisis) o equivalente por carecer en dicho momento de inteligencia y voluntad, pero, como todo, habrá de matizarse el grado de afectación en dicho momento. No obstante, en el caso de estados crepusculares, o de la epilepsia residual, el groso de perturbación no será tan profunda como para la aplicación de la inimputabilidad, debiendo proceder a la eximente incompleta e, incluso, a la imputabilidad plena si la acción se realiza entre las crisis convulsivas pero no en presencia de la misma. Pese a ello, los resultados no son tan sencillos, pues de la necesidad de la valoración individualizada se deduce su relación con el ilícito a efectos de impunidad, más aún cuando se tiene constancia de la posible existencia de intervalos de lucidez.

Especial trascendencia tendría esto último al considerar que la escasa integración sensorio-motriz en el momento de las crisis apenas permite al sujeto ejecutar una acción completa, por lo que quizá deberá analizarse si verdaderamente existiría inimputabilidad en estos casos, todo lo cual se relacionaría más con la naturaleza omisiva de la acción antijurídica -dada las características que definirían al sujeto en dicho estado-, que con una ausencia de acción en sentido penal por imposibilidad de autodirección del individuo.

Incluso en el sentido estricto de la palabra podría llegar a decirse que no se trata de una ausencia de imputabilidad, sino de inexistencia de acción en sentido penal; es decir, la voluntad dirigida hacia un fin -ausente en la epilepsia-, excluiría expresamente los movimientos realizados en el curso de un ataque epiléptico a efectos penales, de manera que la omisión sería la forma más patente ${ }^{46}$.

Pese a lo dicho sobre la epilepsia, nuevamente se hace plausible la complejidad en la estimación de las circunstancias modificativas de responsabilidad de no cerciorarse que, efectivamente, quedaron anuladas tanto la capacidad cognitiva como volitiva de quien actuó ilícitamente. En este sentido baste contemplar la Sentencia del Tribunal Superior de Justicia de Islas Canarias de 8 de mayo [RJ 2002\4734] cuando

\footnotetext{
${ }^{46}$ CEREZO MIR, J., Curso de Derecho Penal Español. Parte General (II). Teoría jurídica del delito (6a
} Edición), Madrid, Tecnos, 1998, p.66. 
apoyándose el acusado en la epilepsia para la modificación de la responsabilidad criminal su apreciación es desestimada. Indica que «el acusado padecía una enfermedad orgánica epiléptica con problemas en el control de sus impulsos, no teniendo afectada su inteligencia, pero sí "parcial" o "ligera" (como se declaró en el plenario) su voluntad por su dificultad para controlar su agresividad, pero que no se había podido determinar que esa impulsividad fuera asociada a la epilepsia, ni estaba postepiléptico ni en estado crepuscular, aclarando que cuando el acusado dijo en relación a los hechos que "se le rompió la mente", no se desconectaba de la realidad, sino que tenía más dificultades para controlarse, pero ello no le era imposible, equivaliendo esa expresión a que se encontraba muy enfadado o agresivo s ${ }^{47}$.

En idéntico sentido, la Sentencia del Tribunal Supremo de 17 de abril de 2002 [RJ 2002\4734] ya indicó respecto a la epilepsia y la implicación por sí misma de una afectación cognitivo-volitiva que «para la apreciación de la eximente, completa o incompleta, de anomalía o alteración psíquica no basta con la constatación de tal defecto, sino que es necesario que se acredite que, a causa del mismo, el que comete la infracción no puede comprender la ilicitud del hecho o actuar conforme a esa comprensión, o que esas capacidades se encuentran profundamente disminuidas»».

Conforme a ello, señala la Sentencia del Tribunal Supremo de 22 de marzo de 2001 [RJ 2001\1994] que «en la determinación de la existencia de estas anomalías a través de la prueba pericial pueden distinguirse dos fases. En una primera se trata exclusivamente de determinar su existencia con todos sus contornos, lo que corresponde a los peritos médicos. Y en segundo lugar la determinación de sus efectos en cuanto a la imputabilidad del sujeto, lo que corresponde en exclusiva al Tribunal sentenciador, que necesariamente ha de tener en cuenta las circunstancias del hecho mismo para ponerlas en relación con la anomalía apreciada por los peritos determinando de esta forma la capacidad de culpabilidad del sujeto en relación con el hecho concreto imputado»».

\footnotetext{
${ }^{47}$ Sentencia del Tribunal Superior de Justica de Islas Canarias de 8 de mayo de 2013 [RJ 2013\279167]
} 
En definitiva, desde hace tiempo la jurisprudencia se ha mostrado acorde en la exigencia de los parámetros valorados para la contemplación de la responsabilidad criminal en quienes padecen una epilepsia, refiriendo que cuando una persona con tal enfermedad hubiese actuado en ausencia de ataques epilépticos habrá de estudiarse el caso concreto para determinar el alcance de su exigibilidad ${ }^{48}$.

Lo cierto es que el bloque de las alteraciones psíquicas vinculadas con las psicosis ha sido de los más admitidos por la jurisprudencia en cuanto a la apreciación de la inimputablidad con exención completa, tal y como dejan entrever la Sentencia del Tribunal Supremo 890/2010, de 8 de octubre [RJ/201017827] o la Sentencia del Tribunal Supremo 688/2007, de 18 de julio [RJ/2007\3799] ${ }^{49}$, pero también es verdad que, tal y como refiere la Sala de lo Militar del Tribunal Supremo de 14 de enero [RJ 2008\1578], «las eximentes deben estar tan probadas como los propios hechos».

Llegado a este punto, habida cuenta que el diagnóstico de TDAH no tendría cabida junto al de la psicosis cuando sus síntomas exclusivamente nazcan de la presencia de este último desorden, de ningún modo podrá plantearse dicho trastorno bajo los preceptos correspondientes del Código Penal que sí amparan las psicosis en general, y la esquizofrenia en particular. De este modo, se vuelve nuevamente a comprender que la existencia comórbida de los cuadros será precisamente lo que permita al TDAH incluirse bajo el artículo $20.1 \mathrm{CP}$, siendo la impulsividad el determinante común pero en ningún caso los síntomas delirantes o la presencia de las alucinaciones, lo cual sería un caracterizador exclusivo de las psicosis.

\subsection{Neurosis y TDAH}

Al igual que sucede con el grupo de las denominadas "oligofrenias", el concepto de "neurosis" es una acepción que, defendida desde la doctrina penal, carece de suficiente apoyo empírico en el campo de la psicología y psiquiatría, las cuales han abandonado aquél término para referirse a otro conjunto de alteraciones. De manera específica, son los Manuales internacionales de la OMS (CIE-10) y de la APA (DSM-5) los que reflejan dicha modificación,

\footnotetext{
${ }^{48}$ Vid. ejemplos en STS de 26 de junio de 1989 [RJ 1989\5226]; STS de 27 de febrero de 2006 [RJ 2006\1812]; y STS de 4 de enero de 2012 [RJ 2012\30495].

${ }^{49}$ Otros ejemplos en STS 63/2006, de 31 de enero [RJ 2006/2851]; STS 1031/2005, de 26 de septiembre [RJ\2005\8610]; y STS 399/2000, de 10 de marzo [RJ\2000\1709].
} 
adoptándose un tipo de nomenclatura internacional que ha día de hoy sustituye el concepto de "neurosis" para hacer alusión a otro elenco de alteraciones de sintomatología relacionada.

Siguiendo a la Real Academia Española de la Lengua (RAE), el término neurosis describiría a una «enfermedad funcional del sistema nervioso caracterizada principalmente por inestabilidad emocional», lo que igualmente pudiera resultar en una definición demasiado extensa, e incluso ambigua, que permitiría la inclusión de diversas patologías bajo dicha denominación. Por su parte, autores como Orts Berenguer y González Cussac, definen la neurosis como simples reacciones vivenciales anómalas y que pueden dar lugar a exención plena o incompleta de la imputabilidad ${ }^{50}$.

En cualquier caso, existiendo diferentes trastornos que pudieran ser interpretados como neurosis, lo cierto es que entre los cuadros clínicos comúnmente asociados a tal denominación se hallarían las psicopatologías relacionadas con la depresión y ansiedad (fobias, estrés postraumático, crisis de angustia), pudiendo albergar incluso algunas alteraciones vinculadas al sueño, trastornos sexuales, bipolares, adaptativos, somatoformes, del control de los impulsos, o disociativos.

Ahora bien, la relación de aquél concepto con las alteraciones descritas previamente no hay que entenderla sobre la base de lo contemplado por la doctrina penal, sino sobre el vínculo del conjunto de patologías mentales que pudieran tener su base en la sintomatología neurótica, sea sensorial, emocional, motor, neurofisiológico, o de cualquier otra índole. Lo cierto es que dicha correspondencia podrá estar presente en otras tantas enfermedades, sean o no mentales, debiendo exclusivamente interesar al Derecho penal en este momento las que afecten al estado mental pero, de manera más específica, las que supongan una alteración severa en la faceta intelectiva y volitiva.

Pese a lo dicho en relación al empleo de aquélla acepción, lo cierto es que la jurisprudencia ha venido matizando el sentido de las neurosis, para lo cual emplea un

${ }^{50}$ ORTS BERNEGUER, E. y GONZÁLEZ CUSSAC, J. L., Compendio de Derecho Penal... cit., p.188; y MUÑOZ CONDE, F. y GARCÍA ARÁN, M., Derecho Penal. ... cit., p.188. 
"apellido" en tal catalogación. Ejemplo de ello serían las denominaciones utilizadas para describir la sintomatología presente en el sujeto, como sería el caso de la neurosis depresiva (Sentencia del Tribunal Supremo 1958/2013, de 17 de octubre de 2013 [JUR\2013\338399]), la neurosis de angustia (Auto del Tribunal Supremo en alguna 1606/2012, de 11 de octubre de 2012 [JUR\2012\346426]), la neurosis postraumática (Sentencia del Tribunal Supremo 697/2012, de 2 de octubre de 2012 [RJ(2012\9460]), la neurosis histérica (Sentencia del Tribunal Supremo de 12 de abril de 2012 [JUR\2012\184475]), o incluso la mixta bajo la denominación de neurosis depresiva ansiosa (Sentencia del Tribunal Supremo de 13 de julio de 2011 [JUR\2011\6484]), indicando concretamente respecto a esta última su especial cronicidad e involución. Además, cada una de ellas responde a unos matices sintomáticos bien distintos. Así por ejemplo en el caso de la primera, la neurosis depresiva se caracterizaría, como indica el Auto del Tribunal Supremo de 24 de noviembre de 2011 [JUR\2012\21645], por una «gran labilidad emocional, llanto fácil, baja autoestima, anhedonia, bloqueo psicomotor, sueño no reparador e ideación catastrófica que interacciona severamente con sus actividades de la vida diaria, cefaleas tensionales, fallos de memoria ocasionales», entre otros aspectos ${ }^{51}$.

En este contexto, si bien pudiera seguir estando presente el concepto de "neurosis" como tal, lo verdaderamente interesante resultaría de la aplicación práctica que hacen los Tribunales españoles, pues al especificar el tipo permiten conocer qué alteraciones pudieran tener mayor cabida bajo dicha acepción.

Explicada la situación anterior, se podría afirmar que dentro de la cláusula abierta redactada por el legislador en el artículo 20.1 CP, así como la no menos restrictiva empleada por la doctrina penal para describir al conjunto de alteraciones mentales permanentes, las neurosis representarían el pequeño cajón desastre que permitirá albergar -teóricamente hablando-, un amplio grupo de cuadros clínicos relacionados con la sintomatología neurótica. Pese a ello, si bien es cierto que sería destacable el esfuerzo tanto doctrinal, como

\footnotetext{
${ }^{51}$ En relación a lo indicado cabría poner de manifiesto que la presencia de las patologías mentales son comunes en todos los ámbitos del Derecho, a pesar de dedicar su tratamiento a lo concerniente al ámbito penal en esta ocasión. A modo de ejemplo, y concretamente en relación a las neurosis, otras área afectadas podían ser lo Social y lo Contencioso, como dejan entrever el caso del Auto del Tribunal Supremo de 24 de noviembre de 2011 [JUR\2012\21645] y de la Sentencia del Tribunal Supremo de 13 de julio de 2011 [JUR\2011\6484], respectivamente.
} 
especialmente en la praxis jurisprudencial, por especificar cuáles de estos últimos trastornos mentales podrían llegar a tener algún tipo de vínculo con lo exigible por el sistema mixto del Código.

En lo que atañe al trastorno por depresión, podría decirse que se trata de una psicopatología muy discutida en cuanto a su consideración en la imputabilidad, tendiendo por lo general a beneficiarse de la inimputabilidad a raíz de la comorbilidad clínica. Así lo pone de manifiesto la Sentencia del Tribunal Superior de Cataluña de 25 de julio [RJ 2013\305620], donde a un sujeto con trastorno depresivo mayor en presencia de sintomatología psicótica le acaba siendo aplicada la eximente incompleta de anomalía o alteración psíquica fundada, principalmente, en los síntomas psicóticos. Se indica a su vez que «en el momento de producirse los hechos, a resultas de la referida afectación patológica psiquiátrica, sufría una alteración o anomalía mental que mermaba levemente su capacidad de comprender lo ilegal de su conducta o ligeramente mermada su capacidad de refrenar su impulsividad al cometerla, presentando ligera y levemente alteradas sus facultades volitivas, cognoscitivas e intelectivas debido a la referida enfermedad mental $>{ }^{52}$.

Como puede apreciarse, la valoración jurídico-legal es bastante controvertida cuando se trata de analizar el estado psíquico en el momento exacto en que el sujeto llevó a cabo la acción ilícita, a sabiendas de que lo interesante en términos de la cuestión sobre la inimputabilidad aludiría a la "comprensión" y "autodeterminación" de la conducta. Se trata de una patología muy compleja por cuanto presenta síntomas muy diversos y en grados bien distintos, pudiendo llegar a la exención plena, entiendo, en casos extremamente excepcionales.

De sobra es conocida la relación bidireccional existente entre los trastornos por depresión y el TDAH, de manera que no sólo los menores y adultos con diagnóstico de TDAH presentan más probabilidad de desarrollar un trastorno del estado de ánimo -así

\footnotetext{
${ }^{52}$ Sentencia del Tribunal Superior de Cataluña de 25 de julio [RJ 2013\305620]
} 
denominados hasta $2013^{53}$-, sino que también los sujetos con esta última patología muestran más probabilidad de presentar un TDAH.

La depresión en niños se asocia con manifestaciones de irritabilidad, negativismo, problemas sociales, disfunción a nivel escolar y trastornos somáticos, de manera que pudieran pasar inadvertidos al ser vinculados a las rabietas propias de la edad o, más aún, al distar significativamente conforme a aquellos síntomas que se conocen para la misma en los adultos (tristeza, falta de motivación para realizar actividades diarias, sensación de fatiga, etc.). La distraibilidad y baja tolerancia a la frustración serían aspectos comunes a ambas patologías, de manera que reuniendo los requisitos expresos para cada una de ellas podrán diagnosticarse de manera conjunta. En este sentido, especial consideración tiene la advertencia previamente mencionada, donde la irritabilidad en menores pudrá comprenderse como síntoma de la depresión, no debiendo achacarla en exclusividad a una derivación hacia el TDAH como consecuencia de la escasa tolerancia a la frustración que ambos presentan.

Según Barkley, no sería poco común hallar menores con repercusiones anímicas como consecuencia de sus propios comportamientos impulsivos, pudiendo encontrar en muchas

\footnotetext{
${ }^{53}$ Habría que indicar que si bien en ediciones anteriores del Manual Diagnóstico y Estadístico de los Trastornos Mentales, bajo la inclusión de los denominados "trastornos del estado de ánimo", se encontraban el trastorno bipolar y el trastorno depresivo (DSM-IV, pp.324 y ss.), la revisión de la Asociación de Psiquiatría Americana del año 2013 separa ambos trastornos en apartados independientes. Si bien se consideran las condiciones diagnósticas más comúnmente diagnosticadas en Psiquiatría (DSM-5, p.xiiii), y siendo la característica común de los mismos sigue siendo la alteración del estado de ánimo, se entiende la necesidad a efectos prácticos de discernir las peculiaridades de cada uno de estos trastornos. De este modo, se sitúa ahora el trastorno bipolar y otros trastornos relacionados entre los referidos al espectro de la esquizofrenia y psicóticos y los propios trastornos depresivos, pues se comprende el presente trastorno como un «puente entre dos clases diagnósticas en términos de sintomatología, historia familiar, y genética") (DMS-5, p.123). Igualmente, habría que indicar respecto al trastorno depresivo que se incluye un nuevo diagnóstico para menores de edad bajo la denominación "trastorno de desregulación del humor disruptivo", en relación a la presencia continua de comportamientos extremos de falta de control y persistente irritabilidad (DSM-5, pp.155 y ss.). diagnóstico este último que considero de especial relevancia si se tienen en consideración las características propias del TDAH.
} 
ocasiones que cumplan los criterios para el trastorno por depresión mayor ${ }^{54}$. Sus características residen en la irritabilidad, sintomatología depresiva persistentes, tristeza, anhedonia, culpabilidad o autorreproche, pensamientos suicidas, o aislamiento social, presentarse conjuntamente con el TDAH en torno al 15\%-30\% de niños y adolescentes ${ }^{55}$.

Ahora bien, las consecuencias de tal co-ocurrencia pueden llegar a ser extremas en tales individuos. Una de las cuestiones más interesante al respecto alude a la probabilidad de los sujetos que presentan un trastorno depresivo de realizar intentos autolesivos, concretamente suicidio. De manera específica, el estudio llevado a cabo por la Universidad de Chicago en 2010 advierte que el 18\% de los niños diagnosticados con TDAH sufren depresión en la adolescencia (diez veces más de lo considerado en población general), siendo las consecuencias más devastadoras de ello la probabilidad de suicidio calculada; esto es, ante la presencia de tales diagnósticos, niños con inicio temprano de TDAH tienen cinco veces más probabilidades de haber pensado en el suicido al menos una vez, y dos veces más de haberlo intentado ${ }^{56}$. Se trata de un hecho que se magnifica además cuando se tiene en cuenta la presencia de otras patologías,

\footnotetext{
54 BARKLEY, R.A., «Primary Symptoms, Diagnostic Criteria, Prevalence, and Gender Differences»), in Russel A. Barkley, Attention-Deficit Hyperactivity Disorder. A Handbook for Diagnosis and Treatment, $\left(3^{\text {rd }}\right.$ Edition), London, The Guildford Press, 2006, p.623.

${ }^{55}$ En relación a las cifras de co-ocurrencia, el estudio realizado por Biederman, Faraone, Mick, y Lelon, muestra que aproximadamente el $70 \%$ de los niños con Depresión severa o media cumple criterios para el TDAH, afirmando a su vez que conforme más temprano es la edad de inicio de la depresión más alta será la prevalencia del TDAH en dichos niños. Concretamente, en base a la relación directa que se establece conforme a la probabilidad de manifestación conjunta según la edad, afirman que mientras en niños hasta 7 años el porcentaje es del 84\%, en niños mayores dicha cifra disminuiría hasta el 66\% (8-12 años) e incluso hasta el 39\% (13-18 años) con el paso del tiempo ${ }^{55}$. Pese a ello, las cifras obtenidas no sólo varían con la edad, sino que también las mismas se ven modificadas en base al contexto de estudio de dicha prevalencia, así como en base al grado o número de genes compartidos entre ambos trastornos. Más información en BIEDERMAN, J.; FARAONE, S.V.; MICK, E. and LELON, E., «Psychiatric comorbidity among referred juveniles with major depression: fact or artifact?», Journal of the American Academy of Child \& Adolescent Psychiatry, Vol.34, 1995, pp.579-590; BIEDERMAN, J.; FARAONE, S.V.; KEENAN, K.; BENJAMIN, J.; KRIFCHER, B.; MOORE, C.; SPRCIH-BUCKMINSTER, S.; UGAGLIA, K.; JELLINEK, M.S. and STEINGARD, R., «Further evidence for family- genetic risk factors in attention deficit disorder: patterns of comorbidity in probands and relatives in psychiatrically and pediatrically referred samples», Archives of General Psychiatry, Vol.49, 1992, pp.728-738; y POPPER, C.W.; GAMMON, G.D.; WEST, S.A. and BAILEY, C.E.; «Disorders Usually First Diagnosed in Infancy, Childhood and Adolescence», in Robert E. Hales and Stuart C. Yudofsky, Textbook of Clinical Psychiatry (4 ${ }^{\text {th }}$ Edition), Washington, The American Psychiatry Publishing, 2003, p.843, respectivamente.

${ }^{56}$ CHRONIS-TUSCANO; A.; MOLINA, B.; PELHAM, W.; APPLEGATE, B. and DAHLKE, A., «Children with $A D H D$ at increased risk for depression and suicidal thoughts as adolescents», University of Chicago, 2010. Estudio subvencionado por de The National Institutes of Health Recurso electrónico disponible en: http://www.uchospitals.edu/news/2010/20101004-adhd.html.
} 
como pudiera ser la vinculación de aquéllos con los trastornos de conducta, así como con los trastornos relacionados con sustancias. Conforme a ello, la presencia de un mayor número de síntomas relacionados con la sintomatología depresiva o ansiógena, así como el trastorno oposicionista-desafiante y de conducta en niños con TDAH, predice de manera elevada y significativa el riesgo de manifestar una depresión en años posteriores. En este sentido, se aprecia la concomitancia del trastorno depresivo con una gran variedad de sintomatología presente en muy diversos cuadros patognomónicos, hecho que favorece su aparición conjunta ${ }^{57}$.

Este es precisamente el problema que surge en torno a la relación con la criminalidad $y$, en consecuencia, conforme al tratamiento de los actos ilícitos cometidos. Evidentemente existe una elevada probabilidad de apreciación co-ocurrente, así como de que dicha comorbilidad sea considerada como factor criminógenos en el desarrollo de conductas ilícitas pero, ¿realmente existe una merma suficiente en la esfera cognitiva o afectiva como para apreciar exención de responsabilidad criminal?

No hay una regla general para dar respuesta a esta cuestión con independencia de la psicopatología que se trate, incluso las psicosis, pero de lo que sí se está claro es en el hecho de admitir que el TDAH, siguiendo los postulados doctrinales y jurisprudenciales, muy excepcionalmente recibirá el beneficio de la inimputabilidad cuando ya de por sí las neurosis parecen no alcanzar dicha exención.

Otro tanto de lo mismo sucede con la ansiedad y sus síntomas o alteraciones conexas, diferentes estudios epidemiológicos señalan que el TDAH y el trastorno de ansiedad serían los problemas psiquiátricos más prevalentes en la infancia y adolescencia ${ }^{58}$-lo que no quita que trastorno oposicionista-desafiante y de conducta sean los dos que se presentan con mayor

\footnotetext{
${ }^{57}$ LEWINSOHN, P.M.; ROHDE, P. and SEELEY, J.R., « «Psychosocial risk factors for future adolescent suicide attempts»), Journal of Counsulting and Clinical Psychology, Vol. 62, 11994, 297-305.

${ }^{58}$ Vid. YOO, H.I.; CHO, S.C.; KIM, B.N.; KIM, S.Y.; SHIN, M.S. and HONG, K.E., «Psychiatric morbidity of second and third grade primary school children in Korea», Child Psychiatry and Human Development, Vol.36, №.2, 2005, pp.215-225 y COHEN, P.; COHEN, J.; KASEN, S., VELEZ, C.N.; HARTMARK, C.; JOHNSON, J.; ROJAS, M.; BROOK, J. and STREUNING, E., «An epidemiological study of disorders in late childhood and adolescence-I. Age- and gender-specific prevalence»), Child Psychological Psychiatry, Vol.34, No.6, 1993, pp.851-867.
} 
frecuencia de manera co-ocurrente con el primero, así como los que mayor peso suponen en el vínculo TDAH-conducta antisocial-. La inquietud psicomotriz o la falta de concentración, serían algunos de los síntomas que pudieran apreciarse de manera común tanto en los Trastornos de Ansiedad como en el TDAH; es más, a cualquiera de los niveles sintomáticos de este último pudieran apreciarse aspectos confusos respecto de aquél. Así por ejemplo, entre los síntomas externalizantes que pudieran llevar a confusión se encontraría también la agitación producto del estrés experimentado, aunque se vivencia en cortos períodos de tiempo. Igualmente, la ansiedad anticipatoria, la aprensión, incontrolabilidad, miedo, y preocupación, no serían rasgos prototípicos del TDAH.

La Sentencia del Tribunal Supremo 932/2013, de 4 de diciembre 2013 [RJ 2014\486] afirma que la eximente incompleta, así como la atenuante analógica muy cualificada, podrán apreciarse en los casos de gran intensidad convulsiva, siempre que además ello suponga una conexión incuestionable dada su «naturaleza de factor criminógeno que genera una delincuencia funcional»s. Pese a ello, refiere que la neurosis sufrida por el sujeto, no siendo de carácter compulsivo, no tendrá incidencia en la capacidad de conocer (ilicitud de la acción), a lo que en todo caso deberá valorarse la capacidad decisoria.

Respecto a lo anterior, habría que decir a su vez que los trastornos por depresión y de ansiedad se definen como alteraciones que podrían aparecer conjuntamente, no siendo de extrañar este hecho. Prueba de ello se observa en el Auto del Tribunal Supremo 24 de abril de 2014 [JUR\2014\163275] refiere crisis de angustia y de pánico, así como trastorno de tipo afectivo que acompaña a la neurosis y distímico que desemboca en depresión; así como el Auto del Tribunal Supremo de 20 de noviembre 2013 [JUR\2014\14150], relativo a una situación de neurosis depresiva crónica con trastorno distímico, ánimo depresivo y agarofobia.

Por último, cabría destacar la conocida como neurosis o síndrome de renta (Código F68.0 de la Clasificación Internacional de Enfermedades o CIE), consistente en la elaboración psicológica de síntomas somáticos. Expresamente, desde la OMS se indica que desarrolla un síndrome comportamental de búsqueda de atención (histriónico) que a menudo incluye también quejas que no son de origen somático, pudiendo parecer asemejarse a la simulación 
cuando vengan derivadas indemnizaciones consecutivas a accidentes o lesiones; sin embargo, el síndrome no suele remitir una vez el litigio ha finalizado con éxito.

Desde el Tribunal Supremo en alguna ocasión se ha hecho mención a dicho desorden, tal y como pone de manifiesto el Auto de 25 de junio de 2014 julio [JUR 2014\188271] al revelar que «se trata de un trastorno psicógeno en el que se produce la exacerbación de lesiones traumáticas (...) no quiere decir alteración de juicio y raciocinio. (...) el resultado de su diagnostico de trastorno depresivo severo y antiguo. (...) podría tratarse de un síndrome de renta puesto que reúne alguna de las características: focalizar todas las experiencias en síntomas y tendencia exagerada a buscar compensación de los síntomas. (...) se puede descartar que simule o invente, tiene un sufrimiento psíquico que no es capaz de manifestar, ella tiene un daño real, es la verdad de su percepción, un daño interno por un sentimiento de haber sido maltratada y con esos comportamientos encuentra alivio de su sufrimiento psíquico»» ${ }^{59}$.

\subsection{Oligofrenias y TDAH}

Antes de comenzar con el análisis penal propiamente dicho, habría que realizar algunas puntualizaciones respecto a las oligofrenias, comúnmente identificadas con el denominado "retraso mental" (RM). De manera específica cabría decir que con el DSM5 se procede al cambio de la denominación de RM, al igual que suprimen los grados de severidad propuestos en la Edición anterior ${ }^{60}$, manteniéndose por otra parte los criterios

59 Sentencia en relación al Auto del Tribunal Supremo 612/2013, de 21 de marzo de 2013 [JUR\2013\118161]

60 Dicha distinción se hace presente en el ámbito jurídico. Así, respecto a la Oligofrenia, se recuerda desde la Sentencia de la Audiencia Provincial de Madrid 457/2011, de 16 de mayo [JUR 2011\248477] que se califica como «una perturbación de la personalidad del agente de carácter endógeno que supone una desarmonía entre el desarrollo físico y somático del sujeto y su desarrollo intelectual o psíquico, constituyendo un estado deficitario de la capacidad intelectiva, que afecta al grado de imputabilidad. Partiendo de las pautas psicométricas que ofrecen los resultados de los test de personalidad e inteligencia, se viene considerando que cuando la carencia intelectiva es severa, de modo que el afectado tenga un coeficiente inferior al $25 \%$ de lo normal, la oligofrenia debe de calificarse de "profunda" y su consecuencia penal debe ser la apreciación de una eximente completa; cuando el coeficiente se sitúa entre el 25 y el $50 \%$ la oligofrenia puede calificarse como de mediana intensidad, correspondiéndole penalmente el tratamiento de una eximente incompleta. $Y$ cuando el cociente intelectual se encuentra situado entre el 50 y el 70 por 100, se califica de oligofrenia ligera o de mera 
del coeficiente intelectual en base a la interferencia en la función adaptativa y distinguiendo la severidad de la disfunción según sea suave, media, grave y profunda conforme a la afectación en el dominio conceptual, práctico y/o social. Concretamente, se procede al diagnóstico cuando el CI sea inferior a 70. Por otro lado, las características de inatención, fracaso escolar, e impulsividad, serían comunes a ambos Trastornos. Igualmente, los niños con CI bajo pudiera parecer que no prestan la suficiente atención, debiendo distinguir estos signos similares en sujetos con TDAH.

Si bien en este sentido podría entenderse un avance significativo en cuanto se dejan al margen los aspectos más negativos, estigmatizantes, discriminatorios $\mathrm{y}$ peyorativos de aquella acepción para dar lugar al "trastorno desarrollo intelectual" o, lo cierto es que su relación con el TDAH no varía. De esta forma, cada uno de ellos sigue manteniendo sus particularidades específicas, mientras el diagnóstico diferencial se asentará en la presencia de síntomas de desatención o hiperactividad-impulsividad fuera del ámbito académico y cuando sean excesivos para la edad del menor.

Pero dejando al margen lo anterior, el interés que suscita dicha alteración responde a su comprensión desde el ámbito penal, y lo hace sobre la base de no ser el concepto de "oligofrenia" un término empleado desde las Ciencias de la Salud.

En lo que atañe a su definición y delimitación a nivel jurisprudencial, indica la Sentencia de la Audiencia Provincial de Alicante 829/2012, de 20 de noviembre [ARP 2013184] que «la oligofrenia, retraso mental o también denominada debilidad mental constituye -según se describe en la doctrina científica- un trastorno permanente del individuo producido en los momentos iniciales de su maduración psicosomática debido a factores diversos (congénitos o adquiridos) que se traduce en un déficit de todas o

debilidad o retraso mental, debiendo ser acreedora de una atenuante analógica, siendo por lo general plenamente imputables los afectados por una mera torpeza mental, con coeficientes situados por encima del $70 \%$ », a lo que añade «todo ello sin excesiva rigidez». Otro ejemplo de comorbilidad de un Retraso Mental con TDAH puede apreciarse en la Sentencia de la Audiencia Provincial de Cuenca 40/2014, de 4 de abril [JUR 2014\118699]. 
algunas estructuras orgánicas y por una perturbación de la vida instintiva, volitiva y afectiva, determinando el desarrollo de la personalidad en su globalidad» ${ }^{61}$.

Del mismo modo, la Sentencia del Tribunal Supremo 189/2015 de 19 de febrero [JUR\2015\81616] lo asemeja a la inteligencia límite, o "profunda" en los términos referidos anteriormente, indicando en todo caso que para la aplicación de la eximente completa del artículo 20.1 CP el sujeto habrá de desconocer la existencia, habiéndole sido impedido el «comprender la antijuricidad de su acción o actuar conforme a esa comprensión»».

Las condiciones del trastorno de desarrollo intelectual marcan una evidente distinción con el TDAH en cuanto a su posible cabida dentro del artículo 20.1 CP, principalmente en lo que se refiere a la afección sobre la facultad intelectiva y a las consecuencias que su presencia pudiera suponer en grado severo pues, de no experimentar un nivel suficiente de afectación, la apreciación de aquella circunstancia modificativa de la responsabilidad criminal se vendrá aplicando en base a los criterios generales empleados para el resto de alteraciones descritas por la doctrina penal.

En lo que respecta a la presencia conjunta de la oligofrenia-TDAH en los Tribunales españoles, lo cierto es que la existencia del primero tiende a llevar beneficios para el segundo, no siendo así al contrario; no obstante a lo anterior, ya se advirtió en su momento que ninguna calificación clínica per se conllevará la exención de responsabilidad. A modo de ejemplo destaca la Sentencia de la Audiencia Provincial de Alicante 457/2011, de 16 de mayo [JUR 20111248477], en la que se aprecia diagnóstico de retraso mental moderado, TDAH, mal control de los impulsos, baja tolerancia a la frustración, alteraciones de conducta, grado de minusvalía del 65\%, y una valvulopatía unida a una enfermedad de tipo inmunológico, fallando expresamente el no haber lugar a la apreciación de la atenuación analógica. Del mismo modo hace la Sentencia de la Audiencia Provincial de Castellón de 29 de octubre de 2013 [JUR 2014\120484] la cual, siendo diagnosticado el apelante con una oligofrenia (capacidad intelectual límite con CI 80) y un trastorno de personalidad, a lo que además se une un trastorno de tics

\footnotetext{
${ }^{61}$ Vid. en idéntico sentido la Sentencia de la Audiencia Provincial de Alicante 829/2012, de 20 de noviembre [ARP 2013\84]
} 
motores y el TDAH, se llega a señalar que «los trastornos referidos no tenían una incidencia siquiera mínima en la imputabilidad», pues a pesar de poder existir una variada y múltiple comorbilidad diagnóstica siempre habrá de atenerse a la situación concreta que propició la acción imputada.

Por su parte, la Sentencia del Tribunal Supremo 849/2014, de 2 de diciembre [RJ 2014\6353], aplica la atenuante muy cualificada para uno de los imputados por considerar la existencia de un déficit leve de percepción intelectual. De este modo, señala el Tribunal que el sujeto «se halla afectado por un cuadro permanente e irreversible de oligofrenia leve, (...). Tiene mermadas sus capacidades cognitivas y volitivas»; pese a ello refiere que "tiene capacidad para desenvolverse en la vida en todos los actos que sean cotidianos y rutinarios, pero si bien puede conocer lo que está bien y lo que está mal de lo que hace, es muy influenciable, no discerniendo correctamente fuera de lo acostumbrado y habitual», a lo que termina concluyendo que se trata de una «anomalía psíquica le hace muy vulnerable a las influencias externas, especialmente las provenientes de su entorno más próximo».

Vuelven a surgir ambigüedades en lo que respecta a la catalogación de los cuadros clínicos. Así, en determinadas Sentencias, las alegaciones efectuadas por la defensa llevan a querer contemplar la apreciación del TDAH dentro del grupo de patologías previamente mencionado, como sería el caso de la Sentencia de la Audiencia Provincial de Alicante 2/2012, de 9 de enero [JUR 2013 159101] donde se afirma, por parte de la defensa, que «se le aplique la eximente del artículo 20.1 CP por un supuesto trastorno adaptativo y por déficit de atención con hiperactividad y, en todo caso, a manos la atenuante del artículo $21.2 \mathrm{CP}$ de grave drogadicción». Igualmente para el caso de la Sentencia de la Audiencia Provincial de Navarra 140/2008, de 13 de octubre [JUR 2009\52119], en la que la defensa alega que «el acusado, diagnosticado de un trastorno por déficit de atención de hiperactividad, tipo combinado, presentaba, en el momento de cometer los hechos, una severa restricción de su facultades volitivas e intelectivas», llevando en este caso a la apreciación de eximente incompleta por enfermedad mental (atenuante muy cualificada) junto con la atenuante de embriaguez.

Por su parte, no habría que olvidar la otra cara de la moneda; esto es, que tratándose de psicopatologías del neurodesarrollo, o de inicio en la infancia, suelen 
generan una mayor vulnerabilidad en quien las padece. Esto es precisamente lo que señala la Sentencia de la Audiencia Provincial de Alicante 829/2012, de 20 de noviembre [ARP 2013184], donde se aprecia la co-ocurrencia de aquel cuadro con un retraso mental leve-moderado en un menor víctima de abuso. Además, muy ejemplificativa resulta esta Sentencia por cuanto permite mostrar las consecuencias psicológicas que se deprenden para el menor que sufre dicho tipo de maltrato, más aún cuando ya existe sintomatología clínica de manera expresa. Refiere la Sala que «a consecuencia de los hechos el menor padeció estrés postraumático, tristeza, angustia, irritabilidad y una importante interferencia en su desarrollo psicosexual», a lo que se añade «lo que ha generado en él la repetición del patrón de conductas sexuales en otro menor»».

\subsection{Psicopatías/Trastornos de la Personalidad y TDAH}

Como señala la Sentencia del Tribunal Supremo 80/2015, de 6 de febrero [RJ2015\515], «los trastornos de la personalidad son patrones característicos del pensamiento, de los sentimientos y de las relaciones interpersonales que pueden producir alteraciones funcionales o sufrimientos subjetivos en las personas y son susceptibles de tratamiento (psicoterapia o fármacos) e incluso pueden constituir el primer signo de otras alteraciones más graves (enfermedad neurológica), pero ello no quiere decir que la capacidad de entender y querer del sujeto esté disminuida o alterada desde el punto de vista de la responsabilidad penal», añadiendo que «en principio no han sido considerados como enfermedades mentales que afecten a la capacidad de culpabilidad del mismo. Y se dice: "en principio" porque: la categoría no nosológica de los trastornos de la personalidad (como antes, la de las psicopatías) incluye una serie de desórdenes mentales ("mental discordes") de contenido muy heterogéneo, por lo que el tratamiento jurídico penal de uno de ellos no siempre será exactamente extrapolable a todos los demás». Similarmente se pronuncia la Sentencia del Tribunal Supremo 633/2014, de 14 de octubre [RJ\2014\4725] al indicar que «las psicopatías o trastornos de la personalidad no presentan siempre la misma intensidad o grado de afectación en quien las padece. Así, en ocasiones, como se lee en diversa jurisprudencia de esta sala, pueden ocasionar trastornos del temperamento y de la afectividad que no se traducen necesariamente en una pérdida, y ni siquiera disminución, de la capacidad de imputabilidad»». 
Se trata de una aseveración no siempre pacífica en la jurisprudencia, siendo prueba de ello la Sentencia de la Audiencia Provincial de Sevilla 251/2009, de 14 de mayo [JUR 2009\312941] cuando afirma que «en la redacción del Código vigente, los trastornos de la personalidad pueden ser considerados dentro del ámbito del artículo 20.1aㅡ, no solo por las valoraciones más modernas de la OMS, sino porque no se exige en el texto exactamente una enfermedad mental sino una anomalía psíquica, categoría en la que pueden incluirse sin dificultad». Se trata de una afirmación reiterada por la Sala de lo Militar del Tribunal Supremo de 17 de enero [RJ $2014 \backslash 3262]$, que viene a indicar cómo la doctrina psiquiátrica admite que la manifestación esencial de este tipo de alteraciones responde a un «patrón de conductas y experiencias internas que se desvían marcadamente de lo que cultural o socialmente se espera (...), se manifiesta en el área de la cognición, en el de la afectividad, en el funcionamiento interpersonal o en el control de los impulsos. Se trata de un patrón de conducta generalmente inflexible y desadaptativo (...) conduce a una perturbación clínicamente significativa»s. Sentencia que igualmente menciona lo ya contemplado en la Sentencia del Tribunal Supremo de 23 de diciembre [RJ 2003\2706], la cual venía a referir que los trastornos de la personalidad «En la actualidad tienen encaje en el artículo 20.1 pues se trata sin duda de anomalías o alteraciones psíquicas, por lo que es necesario atender a sus características y a las peculiaridades del hecho imputado para precisar sus concretos efectos»).

Unido a lo anterior, la Sentencia del Tribunal Supremo 158/2015, de 17 de marzo [RJ 2015\991] que «las psicopatías o trastornos de la personalidad, que son evidentemente una clase de "anomalías o alteración psíquica", pueden encajar en la mencionada eximente incompleta del art. 21.1 cuando, sin excluirlas (lo que en principio no cabe en esta clase de trastornos), afectan con alguna intensidad a la capacidad de "comprender la ilicitud del hecho" o a la de "actuar conforme a esa comprensión". Ciertamente cuando esa intensidad es menor podrá aplicarse la referida atenuante analógica del art. 21.6. No puede olvidarse que estas anomalías psíquicas se caracterizan precisamente por su variedad, no sólo en cuanto a las diferentes formas en que pueden afectar a las diferentes áreas de la estructura espiritual del sujeto, sino porque, por su mismo concepto, son desviaciones de carácter respecto del tipo normal, y esas desviaciones puede ser más o menos acentuadas». 
El concepto de psicopatías en su traducción literal respondería a la existencia de alteraciones de la psique, lo que pudiera resultar demasiado extenso incluso por llegar a poder extrapolarse a todo el conjunto de alteraciones mentales existentes. Pero lo cierto es que a día de hoy la doctrina penal española viene refiriendo tal concepto como sinónimo de los trastornos de la personalidad (TP), tal y como se ha podido apreciar de la redacción literal de las anteriores sentencias pero, ¿sería adecuada tal identificación?

La primera crítica que debiera de realizarse en cuanto a la contemplación de los trastornos de personalidad como psicopatías sería la siguiente: ¿podría considerarse sinónimo el concepto de psicopatías de TP cuando la Psicopatía, en singular, no sería catalogada como un TP? ¿Por qué incluir dicho grupo de anomalías cuando comúnmente los Tribunales la aprecian en base al 21.7 CP? ¿Qué relación habría con el TDAH?

Conforme a la primera de las cuestiones; esto es, al porqué denominar al conjunto de trastornos descritos bajo dicho presupuesto como "psicopatías", si la misma caracterización de la "psicopatía" -en singular-, no se definiría propiamente como un TP sino como un híbrido entre síntomas narcisos y antisociales que no llega a recibir ningún calificativo en el DSM ${ }^{62}$. En esta línea, ¿podría por tanto una alteración no específicamente detallada en los manuales internacionales de diagnóstico psicopatológico llegar a ser objeto de apreciación desde el ámbito penal? Evidentemente la respuesta a ello debe ser negativa, ¿pues cómo se va a considerar desde el Derecho Penal una psicopatología si ésta carece de reconocimiento desde el ámbito de las Ciencias de la Salud? ${ }^{63}$

Extrapolando las implicaciones a otros contextos afines, autores como Pozueco Romero, Romero Guillenas y Casas Barquero indican que tanto desde el ámbito legislativojurisprudencial como penológico-penitenciario, el tratamiento del constructo de psicopatía ha sido poco preciso, disputa acrecentada por la falta de argumentos empíricos para apoyar tales

\footnotetext{
62 Más información en AGUILAR CÁRCELES, M.M., «Psicopatía: actuación desde la Criminología y del Dereecho penal-penitenciario»), en D.L. Morillas Fernández (Dir.) y Rodríguez Ferrández (Coord.), Criminología y Ejecución de penas, Murcia, EDITUM, 2014, pp.71 y ss.

${ }^{63}$ AGUILAR CÁRCELES, M.M., El Trastorno por Déficit de Atención e Hiperactividad... cit., pp.407 y ss.
} 
entidades nosológicas, lo que produce en ocasiones una importante confrontación en lo que se refiere a su comprensión, más aún cuando los términos pudieran venir empleándose como sinónimos e intercambiables cuando en realidad no lo son ${ }^{64}$.

A lo anterior, personalmente entiendo que lo correcto sería el empleo de la denominación de trastornos de la personalidad para definir al conjunto de estas alteraciones sí detalladas como tales por la APA, pues de venir empleando el concepto de "psicopatías" -en plural-, como sinónimo, podría llevar a una importante y trascendente confusión con la acepción "psicopatía" -en singular-, no considerada como un trastorno de la personalidad en sí mismo sino como una disfunción del carácter que presenta tanto rasgos del trastorno de personalidad antisocial como borderline, a lo que se añaden además la diversidad de factores criminógenos que favorecen su inclinación por la criminalidad.

Continuando con las preguntas restantes, es cierto que la visión doctrinal ha venido en su mayoría rechazando la aplicabilidad de la eximente completa para los trastornos de la personalidad, siendo por su parte más debatida la tendencia jurisprudencial aún siendo cada vez más acorde con la inaplicabilidad de la exención. Por ello podría llegar a admitirse, salvo casos excepcionales, que la dirección jurisprudencial actual y mayoritaria conforme a los trastornos de la personalidad rechaza la aplicación de la eximente del artículo 20.1 CP de manera absoluta, aunque diversos autores confirman la necesidad de valorar hasta qué punto dichos trastornos podrían afectar a la capacidad volitiva del sujeto, procediendo en tales casos el posible grado de impunidad ${ }^{65}$.

La interpretación de los Tribunales acerca de la eximente de enajenación mental sustentada en la base de una patología o enfermedad mental con base en un trastorno de la personalidad ha sido muy controvertida. Precisamente, el dilema se sostiene no solo en la diversidad de los propios trastornos de la personalidad, en los cuales su sintomatología en bien

${ }^{64}$ POZUeCO ROMERO, ROMERO GUILLENAS y CASAS BARQUERO, N., «Psicopatía, violencia y criminalidad: un análisis psicológico-forense, psiquiátrico-legal y criminológico (Parte II)», Cuadernos de Medicina Forense, Vol.17, №.4, 2011, pp.175-192.

${ }^{65}$ LÓPEZ-IBOR, J.J., La personalidad en Medicina y sus trastornos, Madrid, Real Academia Nacional de Medicina, 1993, pp.48 y ss. 
distinta, sino por su composición como cuadros clínicos con un patrón estable de comportamiento.

Atendiendo a ello, advierte Caballo que «la personalidad podría considerarse como un patrón de pensamientos, sentimientos y conductas característicos que distingue a las personas entre sí y que persiste a lo largo de tiempo y a través de las circunstancias », a lo que añade «solo cuando dichos rasgos son inflexibles y desadaptativos y causan un malestar subjetivo o un deterioro funcional significativo pueden considerarse como trastorno de la personalidad $»$. En deducción a lo anterior, continúa el autor indicando que se concluirá la existencia de esta Patología cuando: i) esté profundamente enraizada y sea de naturaleza inflexible; ii) sea desadaptativa -especialmente en contextos interpersonales-; iii) es relativamente estable a lo largo del tiempo; iv) deteriore de forma significativa la capacidad de la persona para funcionar; y v) produzca malestar en el entorno del individuo ${ }^{66}$.

El detonante clave y factor determinante en relación al TDAH vuelve a ser la impulsividad. En este sentido, Jiménez Díaz y Fonseca Morales corroboran la existencia de una « destaca la prácticamente nula capacidad de planificación de estos sujetos, siendo habitual que sus frecuentes arrebatos de ira conduzcan a reacciones violentas originadas por motivos nimios» ${ }^{67}$. En la misma línea, Echeburúa refiere que «los trastornos de personalidad implican importantes alteraciones cognitivas, emocionales y relacionales, así como la ausencia de habilidades específicas y de aprendizajes sociales», indicando a su vez que, en determinadas ocasiones, el continuum de anormalidad-normalidad pudiera arroja estados límites poco discriminativos. De manera específica, se plantea el autor en lo que respecta a la sintomatología impulsiva la siguiente cuestión: «¿en qué momento la impulsividad, las relaciones inestables y los sentimientos de vacío rebasan el umbral clínico?» ${ }^{68}$.

\footnotetext{
${ }^{66}$ CABALLO, V.E., "(Conceptos actuales sobre los trastornos de la personalidad», en Vicente E. Caballo (Coord.), Manual de trastornos de la personalidad. Descripción, evaluación y tratamiento, Madrid, Síntesis, 2009, pp.31 y ss.

67 JIMÉNEZ DÍAZ, M.J. y fONSECA MORALES, G.M., Trastornos de la Personalidad (psicopatías). Tratamiento científico y jurisprudencial (2a Edición), Madrid, CESEJ-Ediciones, 2007, p.45.

${ }^{68}$ ECHEBURÚA, E., Personalidades violentas, Madrid, Ediciones Pirámide, 2009, pp.54 y 55.
} 
Parecería lógico no plantear la imputabilidad de quienes actúan motivados a partir de sustratos neurofisiológicos tan potentes como para definir un patrón de comportamiento crónico y estable en el tiempo considerado patológico, más aún cuando su contemplación, como ya se ha indicado, se hace expresa en el Código Penal bajo el grupo de las "anomalías permanentes". Pese a ello, el planteamiento no es tan sencillo, debiendo de valorar detenidamente los criterios exigibles para cuestionarse tal responsabilidad criminal.

Conforme a lo inmediatamente referido, sería cierto admitir que la inimputabilidad observada por co-ocurrencia o comorbilidad diagnóstica con el TDAH se apreciaría cuando existiese alguno de los cuadros con cabida en el artículo 20.1 CP; es decir, oligofrenias, psicosis, neurosis, o psicopatías, sabiendo que en el caso de estas últimas difícilmente se contemplaría la eximente completa. Este sería el caso de la Sentencia de la Audiencia Provincial de Madrid 169/2014, de 18 de marzo [JUR 2014\107630], «la jurisprudencia, como regla general, ha venido valorando los trastornos de la personalidad como atenuantes analógicas»; ahora bien, la pregunta a ello podría ser la siguiente: ¿por qué incluir dicho grupo de anomalías cuando comúnmente los Tribunales la aprecian en base al 21.7 CP? ${ }^{69}$

Dicho ello, considero pertinente hacer un repaso jurisprudencial exhaustivo, y no solo sustentado en la caracterización de los aspectos antes señalados, sino muy especialmente por la vinculación que podría tener con el TDAH, especialmente por el factor criminógeno descrito en relación a la presencia de sintomatología impulsiva y, concretamente, en cuanto al vínculo de dicho cuadro con las alteraciones de la personalidad descritas en el grupo B (TP histriónico, narcisista, antisocial, y límite o borderline) definidos por su dramatización, inmadurez, imprevisibilidad y labilidad anímica.

Dicho grupo o clúster se caracteriza por albergar alteraciones con marcados problemas en la esfera interpersonal, diagnosticando aquéllos desórdenes asociados a características de personalidad dramáticas, emotivas e inestables, siendo además con frecuencia los que comúnmente vienen a presentarse de manera comórbida con el TDAH; es decir, este último

69 AGUILAR CÁRCELES, El Trastorno por Déficit de Atención e Hiperactividad... cit., p.441. 
trastorno puede llegar a considerarse como una psicopatología de riesgo o factor criminógeno en la evolución posterior hacia un trastorno de personalidad, comúnmente del clúster $\mathrm{B}^{70}$.

De manera específica, en relación al desarrollo de la personalidad mencionado previamente, autores como Anckarsäter et al. advierten sobre el impacto que el diagnóstico de TDAH en la niñez pudiera tener en la misma. Unido a ello, pacientes con dicho diagnóstico presentan niveles más elevados de búsqueda de novedades-sensaciones y de evitación del daño, siendo más común a su vez la presencia de trastornos de personalidad pertenecientes al grupo B. En contra, los Grupos A y C se vincularían con patologías previas pertenecientes al trastorno del espectro autista (TEA). Así, respecto a aquella vinculación, indican los autores que el TDAH se asociaría con la configuración de variables temperamentales específicas y un incremento del riesgo de padecer un TP posterior y déficits en la maduración del carácter ${ }^{71}$.

Entre las consideradas personalidades con mayor potencialidad violenta y con un importante vínculo respecto al TDAH se encontraría la personalidad antisocial (trastorno antisocial de la personalidad o TAP) y la personalidad límite (Trastorno límite de la personalidad o TLP), motivo por el cual me detendré en su análisis por ser precisamente las que pudieran tener mayor vínculo o contacto con el Sistema de Justicia.

Tal y como se adelantó en su momento, lo cierto es que la tendencia jurisprudencial de apreciación de la eximente completa para los trastornos de la personalidad deriva más en la excepcionalidad de la eximente incompleta y, en mayor medida, de la atenuante analógica, aun a pesar de cuestionarse tajantemente su aplicabilidad como diagnóstico aislado. A modo de ejemplo, en las siguientes Sentencias del Tribunal Supremo puede observarse como la comorbilidad clínica sería el factor esencial para considerar la existencia de una circunstancia

70 PHILIPSEN, A. «Differential diagnosis and comorbidity of attention-deficit/hyperactivity disorder (ADHD) and borderline personality disorder (BDP) in adults», European Archives of Psychiatry and Clinical Neuroscience, Vol.256, №.1, 2006, pp.142 y ss.

71 ANCKARSÄTER, H.; STAHLBERG, O.; LARSON, T.; HAKANSSON, C.; JUTBLAD, S.B.; NIKLASSON, L.; NYDÉN, A.; WENTZ, E.; WESTERGREN, S.; CLONINGER, C.R.; GILLBERG, C. and RASTAM, M., «The Impact of ADHD and Autism Spectrum Disorders on Temperament, Character, and Personality Development», The American Journal of Psychiatry, Vol.163, $N^{o} .7,2006$, p.1239. 
modificativa de responsabilidad criminal, sea de exención como de atenuación, en el caso de los trastornos de la personalidad; a saber:

- STS de 12 de julio de 1999 [RJ 1999\6648]: asunción de una eximente incompleta a un sujeto con un trastorno de la personalidad con alteraciones de memoria y conducta antisocial, por entender los efectos producidos consecuencia de su adicción a las drogas.

- STS de 30 de junio de 2000 [RJ 2000\5654]: el sujeto padece un trastorno de la personalidad con patología depresiva, ante los cual entiende el Tribunal Supremo la aplicación de la eximente incompleta.

- STS de 6 de octubre de 2000 [RJ 2000\1557]: «las alteraciones de la personalidad pueden operar a través de la anomalía o alteración psíquica pero ello no es suficiente para que pueda ser apreciada la eximente, ni completa ni incompleta, porque la mera presencia de una anomalía o alteración psíquica puede ser irrelevante para la determinación de la imputabilidad de quien la padece, requiriéndose además la anomalía o alteración se interponga entre el sujeto y la norma que establece la ilicitud del hecho de forma que no pueda ser motivado por aquélla o que, pudiendo percibir el mandato o la prohibición contenidos en la norma, carezca de fuerza motivadora para el sujeto porque el mismo se encuentre determinado en su actuación por causas vinculadas a su alteración psíquica que anulen la motivación normativa. Se condena al acusado. Se desestima el recurso de casación por quebrantamiento de forma, infracción de ley e infracción de precepto constitucional»».

- STS de 28 de junio de 2001 [RJ 2001\7022]: ejemplo de "psicopatía" asociada a varios factores, concretamente a la ingesta de alcohol y drogas y a un coeficiente intelectual límite, para el cual se determina la aplicación de una eximente incompleta.

- STS de 4 de noviembre de 2002 [RJ 2002\10854]: al igual que en el caso anterior se estima la disminución de la responsabilidad penal mediante la aplicación de una eximente incompleta por entender la afectación de la drogadicción tanto a la cohesión y organización de la personalidad, como a la voluntad del individuo. 
- STS de 3 de diciembre de 2003 [RJ2003\174]: afirma conforme al tratamiento de un trastorno límite de la personalidad que «nno basta la existencia de un diagnóstico para concluir que en la conducta del sujeto concurre una afección psíquica»s.

- STS de 26 de febrero de 2004 [RJ 2004\2245]: en consonancia con lo inmediatamente anotado, establece esta Sentencia que «la enfermedad es condición necesaria pero no suficiente para establecer una relación causal entre la enfermedad mental y el acto delictivo»s.

- STS de 11 de octubre de 2004 [2004\7319]: trastorno de la personalidad con disforia, ansiedad e irritabilidad, con impulso de ira inapropiada y descontrol, acompañado en el momento de los hechos de la ingesta de bebidas alcohólicas. Se estima que aunque el sujeto gozara de sus capacidades intelectivas sus facultades volitivas se encontraban mermadas, motivo por el que se concluye la aplicación de una atenuante analógica.

- STS de 25 de marzo de 2004 [RJ 2004\2533]: junto con el Tribunal Supremo un importante sector doctrinal rechaza la aplicación de eximente completa, fundamentando su decisión en las capacidades de entendimiento y voluntad de las cuales el sujeto no carece.

- STS de 26 de septiembre de 2007 [RJ 2007\7298] y de 28 de noviembre de 2007 [RJ 2007\782]: «los trastornos de la personalidad pueden definirse como patrones permanentes de pensamiento, sentimiento y comportamientos inflexibles desadaptativos que comportan un significativo malestar subjetivo y/o deterioro de la actividad social o laboralı.

- STS de 3 de diciembre de 2009 [RJ 2010|2016]: existencia de un trastorno de la personalidad antisocial ante el cual se desestima el recurso de una posible aplicación de la eximente incompleta de alteración psíquica o atenuante. 
- STS de 7 de marzo de 2010 [RJ 2010\4061]: «las psicopatías se entienden como trastornos caracteriológicos que originan trastornos de temperamento, de conducta y de la afectividad, (...), sobre las consecuencias jurídicas que en el plano de la imputabilidad generan las psicopatías, ya sea como atenuante analógica como, en algunos casos concretos, como eximente incompleta». En esta sentencia se estima en el sujeto la presencia de una patología de mayor gravedad que un trastorno de la Personalidad, refiriéndose en este caso a un trastorno de tipo psicótico, agravado por el consumo de sustancias y evolucionado a un proceso psicótico del tipo esquizofrenia paranoide. El fallo se traduce en la aplicación de una eximente incompleta.

- STS de 14 de julio de 2010 [RJ 2010\3511]: a diferencia de la sentencia anterior, donde se trataba una psicosis paranoica, en este caso la sentencia versa sobre un sujeto con trastorno de la personalidad paranoide ${ }^{72}$ al cual, por entender mermada su capacidad de raciocinio, se le aplica una eximente incompleta.

Hasta el momento, pudieran plantearse algunas dudas, pero lo cierto es que la jurisprudencia se atiene a lo indicado por la doctrina para los trastornos de la personalidad en cuanto al artículo 20.1 CP solamente en casos muy excepcionales, pues de apreciarse afectación lo harán al amparo del $21.7 \mathrm{CP}$; esto es, se entiende la aplicabilidad de aquél artículo a nivel teórico por cuanto son alteraciones permanentes del carácter, aunque en la práctica la jurisprudencia tienda a matizar cuáles de dichos trastornos y en qué circunstancias llevarán la apreciación de una circunstancia modificativa de la responsabilidad criminal, normalmente por co-ocurrencia (eximente incompleta quedará reservada para casos de especial gravedad como sería la comorbilidad clínica $^{73}$ ) y bajo el reconocimiento de la eficacia atenuatoria del apartado séptimo del artículo 21 CP.

\footnotetext{
72 Habría que señalar que mientras el trastorno paranoide de la personalidad (TPP) se definiría como patrón de desconfianza y suspicacia general hacia los demás, manteniendo algunas características sintomáticas comunes respecto de la esquizofrenia paranoide, se trataría de cuadros clínicos bien distintos. Concretamente, en este último caso se hablaría de una psicosis frente al TPP, el cual entraría a forman parte de las psicopatías.

${ }^{73}$ Como ejemplo de supuesto especialmente grave asociado a otra patología destaca la redacción efectuada en la Sentencia del Tribunal Supremo de 17 de julio [RJ 2008\5159] - Caso 11-M.
} 
Se hace compleja la apreciación de la exención de responsabilidad conforme al artículo

20.1 CP, procediéndose a aplicar algunas de las causas modificativas cuando concurre en el sujeto el efecto del consumo de tóxicos o una alteración como consecuencia de otros cuadros clínicos (p.ej. psicosis). En menor número de casos las resoluciones judiciales han apuntado de una forma más benévola respecto a estos trastornos, pues de hacerlo así sería en casos excepcionales por la marcada severidad de la sintomatología y, como ya he dicho, asociadas a otras patologías. Todo ello resultante en la aplicación de la atenuante analógica ${ }^{74}$ y, en situaciones más excepcionales, de la eximente incompleta.

Retomando la cuestión sobre su vinculación con el TDAH, tanto el trastorno antisocial de la personalidad (TAP) como el trastorno límite de la personalidad (TLP) son los que comúnmente pudieran hallarse de manera co-ocurrente con aquél cuadro y entre ellos $\operatorname{mismos}^{75}$, siendo las características definitorias de tales patologías son bien distintas.

Concretando su relación con el TDAH, Barbudo del Cura, Correas Lauffer y Quintero Gutiérrez del Álamo refieren lo siguiente: a) por su propia definición el TDAH no puede ocurrir en organizaciones de personalidad psicótica ni tampoco sería reducible a un TP; b) el juicio de realidad estaría preservado en el TDAH (distinguen perfectamente el "yo" de "no yo"), integrando la "identidad del yo" los aspectos más significativos (positivos y negativos) y no adentrándose en esa sensación de caos y profunda contradicción experimentada por el paciente fronterizo; c) el adulto con TDAH emplea mecanismos de defensa maduros, presentando dificultades en las relaciones sociales como consecuencia de su propia sintomatología, preservando las relaciones síntomas y seguras, así como no existiendo representaciones distorsionadas, ni síntomas neuróticos crónicos, difusos o polimorfos; esto es, el paciente con TDAH podrá experimentar sintomatología depresiva o ansiosa ligada a

\footnotetext{
${ }^{74}$ Vid. STS de 16 de noviembre de 1999 [RJ 1999\8940]

75 Se trata de un hecho que no resultaría extraño por la elevada comorbilidad que a su vez presentan los propios TP entre ellos; así, siguiendo a Echeburúa, el solapamiento entre los trastornos de la personalidad muy alto, incluso con otras alteraciones clínicas, llegando a afirmar que más de $60 \%$ de pacientes con un trastorno de la personalidad presenta también otra psicopatología. Igualmente, cabría indicar que existe un gran número de factores de criminalidad que quedarías asociados al TAP, apareciendo los primeros síntomas en la niñez e incapacitando al sujeto ya desde el ámbito educativo y profesionalización posterior. Más información en DE CORRAL, P., «Trastorno antisocial de la personalidad», en E. Echeburúa, Personalidades violentas, Madrid, Ediciones Pirámide, 2009, pp.57 y ss.
} 
determinadas situaciones, pero no responderá a la intensidad o gravedad de los síntomas disociativos de aquéllos ${ }^{76}$.

A modo de ejemplo, los niveles elevados de irregularidad e impredecibilidad, las explosiones inesperadas de impulsividad, los patrones de apariencia cambiante pero con bastante dependencia de los demás, los chantajes, los actos de irresponsabilidad, los pensamientos fluctuantes, las relaciones interpersonales caóticas, la automutilación o suicidio, la falta de propósitos para estabilizar sus pensamientos, la incapacidad para mantener estables sus procesos de pensamiento, la inmadurez en el control de la tolerancia a la frustración y de los impulsos, la menor capacidad para procesar información por problemas en su capacidad atencional, el desequilibrio emocional y labilidad afectiva, o la posible tendencia a la inhibición de respuestas emocionales negativas asociadas al dolor y/o culpabilidad, serían algunas de las características definidoras del trastorno límite de la personalidad ${ }^{77}$. Se trata de un conjunto de rasgos sintomáticos de los que algunos pudieran coincidir con el TDAH, como sería el caso de la impulsividad o de la disfuncionalidad a nivel atencional, pero que en ningún caso, por las características del cuadro, llegarán a ser similares.

Por su parte, y aún compartiendo grupo sintomático general con aquél (clúster B), el trastorno antisocial de la personalidad se definiría por un patrón cognitivo rígido e inflexible con incapacidad para demorar el refuerzo o de planear actuaciones a largo plazo, ausencia de temeridad al castigo o de inhibición ante el castigo, falta de consideración de los demás o empatía, trasgresión de las normas, comportamientos temerarios o precipitados espontáneos, mantenimiento de conductas impulsivas dirigidas a objetivos concretos u oposicionista, entre otros aspectos. Nuevamente se observa que las características extrínsecas pudieran guardar semejanzas sin ser patologías idénticas, lo cual lo corrobora la posible co-ocurrencia permitida por la APA. Así por ejemplo, en tal sentido responde la Sentencia de la Audiencia Provincial de Jaén de 6 de mayo [JUR 2013\252516], donde se aprecia que el acusado padecía un trastorno antisocial de la personalidad con una grave adicción al alcohol y otras sustancias

\footnotetext{
${ }^{76}$ Vid. más ampliamente en EY, H., Tratado de Psiquiatría, Barcelona, Masson, 2006, pp.375 y ss., y BARBUDO DEL CURA, E.; CORREAS LAUFFER, J. y GUTIÉRREZ DEL ÁLAMO, F.J., «Caracteriología del adulto con trastorno por déficit de atención e hiperactividad "), en Francisco Javier Quintero Gutiérrez del Álamo, Javier Correas Lauffer y Francisco Javier Quintero Lumbreras, Trastorno de déficit de atención e hiperactividad (TDAH) a lo largo de la vida, Elsevier Masson, 2009, pp.376-382.

${ }^{77}$ CABALLO, V.E., «Conceptos actuales sobre los trastornos de la personalidad... cit., pp.145 y ss.
} 
estupefacientes se alega que aquella patología «disminuía, levemente, sus capacidades intelectivas y volitivas», aun contemplando el supuesto de atenuante analógica de drogadicción $^{78}$. En definitiva, la base continúa siendo la comorbilidad clínica o el hecho de recurrir al amparo en otros trastornos comórbidos para la apreciación de la disminución de la responsabilidad penal.

Dicho ello, sería complejo plantearse la inimputabilidad del TDAH si se atiende a otros cuadros clínicos en los que la estructura de personalidad sería mucho más rígida e inflexible y aún así se cuestiona la modificación de la responsabilidad criminal. Por ejemplo, se ha señalado la posibilidad de llevar conductas autolesivas por quien padece un trastorno límite de la personalidad, comportamiento evidentemente patológico que, si bien no estando dicho proceso de autovictimización contemplado en el Código Penal, daría mucho que pensar sobre quien padece la enfermedad.

El verdadero problema que vuelve a plantearse se apoya en la valoración de la voluntad, en su vínculo con la impulsividad como para ser la misma capaz de anular aquélla, aspecto que no sucede estrictamente ni en estos trastornos mencionados ni en el TDAH. En esta línea, Morillas Fernández indica que «la psicopatía no se aprecia nunca como eximente completa ni incompleta, salvo que se trate de una disminución grave de la capacidad de autodeterminación, coexista con enfermedades mentales o concurran circunstancias excepcionales que afecten gravemente a la inteligencia y voluntad (...), apreciándose la atenuante analógica en los casos en que la psicopatía aparezca asociada a diversas calificaciones como esquizoide, paranoide, $(. .)>.)^{79}$.

Como ya se ha dicho, el Código Penal establece el concepto de imputabilidadinimputabilidad no en la mera presencia de condicionante biopsicológicos, sino en su vinculación con la afectación de las capacidades intelectivas y volitivas en el momento de llevarse a cabo la acción antijurídica (sistema mixto). Por tanto, no procede decretar la inimputabilidad de no encontrarse las capacidades intelectivas y volitivas profundamente

\footnotetext{
${ }^{78}$ Sentencia de la Audiencia Provincial de Jaén de 6 de mayo de 2013 [JUR 2013\252516]

79 MORILLAS FERNÁNDEZ, D. L., «Aspectos criminológico de los psicópatas y asesinos en serie», Cuadernos de Política Criminal, Vol.77, 2002, pp.416 y 417.
} 
afectadas. Si la capacidad de juicio del sujeto se encuentra únicamente alterada, pero no profundamente afectada en el momento de comisión del hecho delictivo, no se procederá a la exención completa de responsabilidad, sino en casos extremos. Sería por ello más adecuado el análisis bajo el prisma de la semi-imputabilidad o imputabilidad disminuida; es decir, conforme a la eximente incompleta (art. 21.1 CP)o en virtud de la atenuante analógica (art. 21.7 CP).

Pese a lo anterior, extraña el pronunciamiento de la Sentencia de la Audiencia Provincial de Alicante 675/2005, de 29 de septiembre [JUR 2008\286751] como manifestación jurisprudencial en la que el TDAH se aprecia como circunstancia modificativa de responsabilidad criminal, no haciéndolo como atenuante, sino como eximente incompleta. No obstante a ello, como indica Morillas Fernández, habría que distinguir más de una inexactitud; a saber: i) se parte de la presencia de un trastorno antisocial de la personalidad junto con un tipo de capacidad intelectual límite del imputado -desde los dos años de edad-; y ii) se advierte que en el momento de la exploración del sujeto no existirían alteraciones cognitivovolitivas pero, tal y como indica el forense, dada la naturaleza del trastorno no sería descartable la afectación parcial de la capacidad volitiva, incluso llegando también a cuestionar en tal sentido lo concerniente a la comprensión.

Conforme a ello, la interpretación por el Tribunal lo lleva a límites insólitos al afirmar que no solo quedaría alterado su comportamiento conductual sino también la comprensión de la gravedad del acto incendiario imputado. Es por ello que razona la necesaria aplicación del 21.1 CP y no del 21.7 CP pero que, en cualquier caso, sería atribuible a un tipo de valoración de piromanía y, de ningún modo, trasladable como tal a los supuestos de modificación o atenuación penal más que por la posible co-ocurrencia de otros factores. En este caso, entiendo que el factor clave sería la capacidad intelectual límite, en la que se ampara el Tribunal para la Resolución bajo el grupo de oligofrenias defendido en el inciso primero del artículo 20 CP. En definitiva, y vistos que los cuadros co-ocurrentes con el TDAH aluden a la piromanía, TAP y limitado coeficiente intelectual, quizá el verdadero fallo del Tribunal habría que comprenderlo bajo un conjunto de razonamientos justificados en dicha comorbilidad clínica. 
Por su parte, cabría destacar la Sentencia de la Audiencia Provincial de Madrid 236/2010, de 17 de mayo [JUR 2010\239161], donde la Sala estima procedente la apreciación de la eximente incompleta del artículo 21.1 en relación con la anomalía psíquica, haciéndolo además de forma muy cualificada. Concretamente, junto a dicha eximente por el actual trastorno oposicionista desafiante (TOD) -denominado en Sentencia como trastorno negativista desafiante (TND)- y TDAH, se alude a la aplicación de una circunstancia modificativa por estado de embriaguez. Nuevamente, el consumo está presente en la valoración penal, aunque esta vez sí se valora de manera independiente de aquellas patologías. No solo es necesaria la existencia de un diagnóstico que aprecie una anomalía o alteración psíquica como elemento biopatológico, sino que a él debe añadirse la comprobación de que tal déficit impide al sujeto, o dificulta en mayor o menor medida, la comprensión de la ilicitud de la conducta o bien la actuación conforme a dicha comprensión. Pero es más, en esta ocasión debiera puntualizarse, por su referencia expresa, hasta qué punto existe, para la apreciación de aquellos cuadros por el $21.1 \mathrm{CP}$, error de identificación con un TP. En relación a esto último muy errónea identificación se desprende de la Sentencia de la Audiencia Provincial de Tenerife 426/2010, de 1 de octubre [JUR 2012\96525], en la que se viene a afirmar expresamente que «la voluntad del acusado estaba ligeramente mermada en atención a su trastorno psíquico (...) el acusado padece un trastorno por déficit de atención con hiperactividad que es un trastorno de la personalidad que, en todo caso, influye limitadamente en la esfera de la voluntariedad»s. Efectivamente no se niega el déficit que a nivel de autodeterminación pudiera representar a este colectivo, pero lo que seguro que no se admitiría es su identificación con un TP, en todo caso, muy inadecuada.

Precisamente en estos trastornos con los que anteriormente a la publicación del DSM5 se asociaba el TDAH es donde podrían hallarse importantes divergencias, ya no solo por su confusión nominativa, sino también por el intento de encuadrarlos junto las alteraciones mentales permanentes descritas por la doctrina penal. Esto es precisamente lo que sucede en la Sentencia de la Audiencia Provincial de Madrid 236/2010, de 17 de mayo [JUR 2010 \239161], en la que se solicita para el acusado la aplicación de la eximente completa del artículo $20.1 \mathrm{CP}$ al entender que, presentando un diagnóstico de trastorno negativistadesafiante asociado a TDAH, «cuando está sometido a tensión (como sucedió en el momento de los hechos enjuiciados) sufre una anulación plena de sus facultades intelectivas y volitivas, tanto para comprender la ilicitud del hecho como para actuar conforme a esa comprensión »». 
En definitiva, como puede apreciarse, si bien la tendencia de los Tribunales españoles no ha sido el atribuir la eximente incompleta al TDAH, se ha podido apreciar que, en determinados supuestos, su presencia comórbida con otras patologías pudiera llevar a admitir dicha circunstancia modificativa de responsabilidad criminal para el conjunto de sintomatología o alteración que caracterizaría al individuo en aquel preciso instante en que se llevó a cabo la acción ilícita.

De lo que se está seguro es de la aplicabilidad de las circunstancias modificativas de la responsabilidad no como consecuencia de una mera valoración jurídico-legal de la alteración, sino de la entidad relevante del hecho y de la patología en cuanto a sus consecuencias fácticas; es decir, sobre la realidad y magnitud efectiva de la incidencia de las facultades intelectivas y volitivas sobre el sujeto y su acción. Se trata de una afirmación que quedaría más corroborada en el caso de las psicosis que en las psicopatías, pues tal y como destaca la aseveración de la Sentencia de la Sala de lo Militar del Tribunal Supremo de 14 de enero [RJ 2008\1578] al referir que "la gravedad inferior de las psicopatías y trastornos de la personalidad, en comparación con las psicosis graves y los niveles más profundos de la oligofrenia, impedirán prácticamente siempre su acogida como circunstancias eximentes, teniendo su normal campo de efectividad en las incompletas con valor de atenuante».

\subsection{Trastorno Mental Transitorio (TMT) y TDAH}

La cuestión de la imputabilidad en sujetos afectados de trastornos mentales orgánicos y autores de hechos delictivos ha llevado al Tribunal Supremo a pronunciarse de manera más homogénea respecto de este colectivo de lo que lo viene haciendo con otros cuadros clínicos. Lo hace poniendo de manifiesto, con carácter general, la posibilidad de aplicación de la eximente completa por anomalía o alteración psíquica como de enajenación mental en estos supuestos. Sin embargo, la anulación de la imputabilidad no siempre ha sido catalogada en tal sentido, pues no solo se ha exigido el componente biológico, sino también el psicológico, conforme a la intensidad de la afectación de la capacidad intelectiva y volitiva. De esta forma, cuando los cuadros demenciales y delirantes no se presenten con intensidad suficiente como 
para proceder a la aplicación de la eximente completa de enajenación mental, pasarán entonces a considerarse bajo la eximente incompleta cuando así se estimase procedente ${ }^{80}$.

En el actual Código Penal, donde la anomalía o alteración psíquica sería la posible casusa de anulación de la imputabilidad, los trastornos orgánicos se incluirían como variantes de las alteraciones psíquicas, debiendo de estar en todo caso valoradas conforme a la intensidad de su manifestación y grado de afectación. La razón de esto último se sostiene en la determinación diferencial de la sintomatología para cada sujeto pues, de expresarse siempre en su máxima intensidad, no cabría en ningún caso plantearse la eximente incompleta.

Respecto al TDAH, la biopatología del mismo no es tan conocida como la que pudiera definirse para estos cuadros, aunque sí que son apreciables alteraciones estructurales y neuroquímicas que conllevasen disfuncionalidad o caracterización del trastorno frente a quienes no lo padecen, no afectando en ningún caso a la capacidad de comprensión ni a la libertad para actuar de acuerdo con la misma, aspecto este último que sí sería representativo de los trastornos mentales orgánicos.

\section{Otras psicopatologías objeto de análisis}

A modo de ejemplificación, pero sin entrar en profundidad en la materia por poder suponer ello una extensión desmedida del trabajo, se detallan seguidamente algunas consideraciones básicas sobre las psicopatologías que atañen al consumo de sustancias y al control de los impulsos en su relación con el TDAH desde el punto de vista del Derecho penal.

3. 1. Trastornos Relacionados con el Uso/Abuso de Sustancias

\footnotetext{
${ }^{80}$ URRUELA MORA, A., Imputabilidad penal y anomalía o alteración psíquica, Granada, Comares, 2003, pp. 50 y ss.
} 
Aun no formando parte de las denominadas "alteraciones permanentes", pero por la especial relación que guarda con el TDAH -principalmente como psicopatología cronificadora de sus secuelas-, se considera pertinente hacer una breve mención a lo estipulado en el apartado segundo del artículo 20 CP. Así, dice el precepto que podrá aplicarse la exención al que "al tiempo de cometer la infracción penal se halle en estado de intoxicación plena por el consumo de bebidas alcohólicas, drogas tóxicas, estupefacientes, sustancias psicotrópicas u otras que produzcan efectos análogos, siempre que no haya sido buscado con el propósito de cometerla o no se hubiese previsto o debido prever su comisión, o se halle bajo la influencia de un síndrome de abstinencia, a causa de su dependencia de tales sustancias, que le impida comprender la ilicitud del hecho o actuar conforme a esa comprensión" ${ }^{81}$.

Junto con las anomalías o alteraciones psíquicas, se aprecian también como medidas de exención de responsabilidad los apartados segundo y tercero del artículo 20 de Código Penal; estas son, la intoxicación plena y síndrome de abstinencia, y las alteraciones en la percepción, respectivamente. En cualquier caso, no se trata de una tarea tan sencilla de valorar, habida cuenta de su posible consideración como eximente incompleta del artículo 21 CP. Además, en el primero de los casos, la dificultad añadida en su caracterización deviene del elevado número de personas consumidoras en este contexto.

La mayor cobertura que pudiera tener el TDAH en el Ordenamiento Jurídico se establece en base al consumo de sustancias así como de los trastornos derivados de tal patología, siendo de sobra conocido que las modificaciones y cambios psíquicos experimentados tras un consumo prolongado podrían traducirse en alteraciones psicológicas más severas, lo que ineludiblemente podría afectar a la facultad cognoscitiva y volitiva, tanto a corto como a largo plazo.

\footnotetext{
${ }^{81}$ Si bien los tres primeros apartados del art.20 CP aluden a la anomalía psíquica, se deja al margen el tratamiento del tercero por su relación expresa con la alteración de la percepción, quedando al margen de la propia definición sintomatológica del TDAH (Art.20.3 CP: "el que, por sufrir alteraciones en la percepción desde el nacimiento o desde la infancia, tenga alterada gravemente la conciencia de la realidad").
} 
En su relación con el TDAH, la sintomatología de un trastorno relacionado con sustancias o, en su caso, de un ingesta que llegara a la intoxicación plena o al síndrome de abstinencia como dependencia extrema de la sustancia, podrían repercutir en la manifestación de aquél. En este sentido, la merma en la capacidad de comprensión podría afectar a la respuesta o foco atencional, del mismo modo que los comportamientos desinhibidos e impulsivos pudieran sostenerse sobre dichos estados. Ahora bien, en este instante, las causas de los efectos del consumo se situarían bajo un claro componente biopatológico deficitario y disfuncional suficiente como para explicar el debate sobre la aplicabilidad de una circunstancia modificativa de la responsabilidad criminal.

Desde este aspecto, no se negaría que el TDAH favoreciera un tipo de comportamiento orientado al consumo, pues concretamente en su tipología hiperactiva-impulsiva podría ser coocurrente. Así, se podría comprender esta patología como un factor de riesgo criminógeno para el desarrollo de un trastorno relacionado con sustancias que pudiera tener o no consecuencias legales. No obstante, dada la diversidad y cantidad de variables intervinientes, no se entenderá tanto como causa sino más bien como mediador sobre la cuestión de la inimputabilidad.

El consumo de sustancias podría ser la variable explicativa de la criminalidad, siendo mucho más plausible en los Tribunales españoles la expresión comórbida entre determinados cuadros clínicos y aquél, a efectos de apreciar la inimputabilidad o disminución de la responsabilidad criminal. A modo de ejemplo, así lo haría teóricamente el trastorno bipolar y el trastorno relacionado con sustancias en comparación con el TDAH, cuyo diagnóstico podrá pasar más desapercibido.

No obstante a lo anterior, como ya se dijo, se trata de una generalidad, pues siempre habrá de atenerse al caso en cuestión. Prueba de ello lo pone de manifiesto la apreciación de la eximente incompleta de alteración psíquica como circunstancia modificativa de responsabilidad criminal se observa en la Sentencia de la Audiencia Provincial de Madrid 265/2006, de 21 de junio [JUR 2006\9812], donde se aprecia la co-ocurrencia del TDAH junto con un trastorno relacionado con sustancias. Pero es más, la trascendencia de destacar esta 
Sentencia frente a otras radica precisamente en la relevancia que se le otorga al TDAH, señalando expresamente que se justifica «la concurrencia de una eximente incompleta de alteración psíquica por padecer sendos trastornos», a lo que además refiere «son susceptibles de tratamiento». De esta forma, se relacionan sendos cuadros clínicos del siguiente modo: «la conjunción de ambos trastornos conlleva que, cuando la persona esté bajo los efectos del alcohol, tiene una mayor pérdida de control, dificultad para controlar sus impulsos y desinhibición de la agresividad latente»».

Junto a la misma, debiera resaltarse la Sentencia de la Audiencia Provincial de Vizcaya 708/2007, de 28 de noviembre [JUR 2008\38715], en la que la aplicación de la eximente incompleta tiene cabida por la mera presencia del padecimiento del TDAH en el momento de los hechos, concretamente un delito contra la seguridad del tráfico o vial, a lo que se añade además el no disponer de permiso de conducción. Ante ello, habría que criticar el hecho de referir la presencia del TDAH en el momento de los hechos, lo cual sería una redundancia tras conocer la caracterización de su diagnóstico, cosa distinta sería su manifestación, más o menos controlada, ante una situación concreta. En idéntico sentido, cabría destacar igualmente Sentencia de la Audiencia Provincial de Palencia 18/2007, de 25 de octubre [JUR 2008\46711] en la que, condenando a dos sujetos por un delito contra la salud pública por tráfico ilícito de drogas, habría que analizar el tratamiento diferencial al que alude el Tribunal en la aplicación de las circunstancias modificativas de la responsabilidad criminal. Concretamente, señala que la atenuante a causa de grave adicción tendrá cabida en uno de los individuos mientras que, en el otro, deberá serle aplicada la exención incompleta de adicción, siendo precisamente en este último caso en el que co-ocurre la politoxicomanía con el TDAH. Por tanto, se deduce el impacto del TDAH en la modificación de la responsabilidad penal; esto es, quizá por sí solo no tendría ningún peso, pero sí lo hace cuando aparece de manera co-ocurrente aun no siendo el diagnóstico principal, sino secundario.

En este contexto, Tiffon Nonis, Arroyo Fernández y Sarrato Martínez, refieren la trascendencia de la llamada trimorbilidad del TLP, TDAH y antiguo TCl con el Abuso de sustancias. El denominador común sería la variable impulsividad, aspecto extensible al TAP ya mencionado pues, tal y como refieren los autores anteriores, los rasgos de personalidad de base de tipo impulsivo evolucionarían con mayor probabilidad hacia el TLP o el TAP, a lo que se añade una inadecuada canalización de la misma en sujetos con TDAH crónico. De este modo, la 
formación de una estructura de personalidad patológica en base a dicha variable podría derivar en el desarrollo de conductas disociales y delictivas ${ }^{82}$.

Se observa nuevamente que dentro de los TP, el TLP y el TAP serían los más vinculantes con el TDAH, siendo precisamente el conector la citada impulsividad, que no la hiperactividad ni, cuanto menos, el déficit atencional. No obstante, si bien es cierto que tal variable favorecería la aparición de las conductas señaladas, también habría que considerar que determinados cuadros clínicos, como pudieran ser los trastornos relacionados con sustancias, acentuarían los rasgos de personalidad de tipo impulsivo, manteniendo y cronificando dichas conductas. Pese a ello, se trata de trastornos bien distintos, estando el TDAH más estrechamente vinculado al deterioro cognitivo y alteraciones del neurodesarrollo que aquéllos.

En definitiva, en el propio DSM se aprecian una gran diversidad de trastornos mentales que incluyen, de un modo u otro, la presencia de comportamientos impulsivos en sus criterios diagnósticos. Es más, tal y como señalan Zapolski, Settles, Cyders y Smith, la impulsividad sería el criterio más común del Manual tras el malestar subjetivo (significación clínica). Aparece en el TLP, TAP, bulimia nerviosa, TDAH, manía, demencia, trastornos relacionados con sustancias, u otros cuadros clínicos relacionados con la ausencia del control de los impulsos como la piromanía, entre otras psicopatologías, siendo común que tal variable actúe contribuyendo a su aparición ${ }^{83}$.

3.2. Trastornos del Control de los Impulsos: la impulsividad como síntoma denominador común

\footnotetext{
82 TIFFON NONIS, B.N.; ARROYO FERNÁNDEZ, A. y SARRATO MARTÍNEZ, L., "Una trimorbilidad forense emergente: TLP + TCI + TDAH y su correlato con el abuso de sustancias tóxicas»), en B.N. Tiffon Nonis, Manual de actuación profesional en Psicopatología Clínica, Criminal y Forense: una dimensión JurídicoLegal, Barcelona, Bosch-Penal, 2009, pp.365 y ss.

${ }^{83}$ ZAPOLSKI, T.C.B.; SETTLES, R.E.; CYDERS, M.A. and SMITH, G.T, «Borderline Personality Disorder, Bulimia Nervosa, Antisocial Personality Disorder, ADHD, Substance Use: Common Threads, Common Treatment Needs, and the Nature of Impulsivity»), Independent Practitioner, Vol.30, №.1, 2010, pp.2023.
} 
De lo que no cabe duda hasta el momento es que, a nivel jurisprudencial, la impulsividad $^{84}$ sigue siendo uno de los aspectos definidores de la posible cabida del TDAH, como patología comórbida, dentro del artículo 20 o 21 CP. Esto es precisamente lo que sucedería con los que una vez ocuparon un capitulo independiente en el DSM y que a día de hoy se unen a los trastornos del comportamiento; esto es, los trastornos del control de los impulsos (TCI) (Vid. Esquema 2 previamente expuesto).

Siguiendo a García Andrade, habría que tener en cuenta las siguientes consideraciones respecto a algunos de los cuadros clínicos que la APA incluía bajo aquél grupo -y que continúa haciendo pese a señalar pequeños matices-; a saber ${ }^{85}$ :

i) En la cleptomanía, el sujeto siente satisfacción en la posesión de aquello que obtiene, no lucrándose de ello o actuando con otros fines distintos a los de aquella gratificación. El individuo busca saciar la angustia exageradamente vivenciada, pues el hecho de producirse beneficios económicos, o actuar mediante cooperación descartaría la hipótesis de la patología a favor de la tipificación de la conducta.

ii) Por lo que respecta al pirómano (piromanía), su fascinación por el fuego así como la contemplación de los efectos del mismo es lo que motiva la producción de incendios, impulso que lo lleva a actuar en tal sentido en contraposición a aquellos en quienes subyace un interés distinto tras la realización del acto (p.ej. incendiario que quema ciertas zonas a sabiendas de que se procederá a su recalificación posterior y obtendrá importantes beneficios).

iii) En relación al ludópata (ludopatía), vuelve de nuevo a actuar el estrés emocional como desencadenante de un impulso incontrolado -hacia el juego en este caso-. Además, al

\footnotetext{
${ }^{84}$ La trascendencia de esta variable viene puesta de manifiesto en el Código Penal bajo la denominación de facultad "volitiva" o, lo que es lo mismo, capacidad de autodeterminación de la conducta.

${ }^{85}$ GARCÍA ANDRADE, J.A., Psiquiatría criminal y forense (2a Edición), Madrid, Centro de Estudios Ramón Areces, 2002, pp.437 y ss.
} 
igual que sucede con los cuadros inmediatamente señalados, las alteraciones impulsivas favorecerían la asociación con el consumo de sustancias, por ejemplo el alcohol, configurándose un cuadro en el que llega a disuadirse la causa principal con las posibles patologías asociadas.

Respecto a lo anterior, señala el autor que «el juego patológico es egosintónico por el hecho de ser consonante con el deseo consciente e inmediato del juego, sin embargo, posteriormente pueden distinguirse lamentaciones y reproches importantes que adentran al ludópata al mundo de la angustia, generadora en muchas ocasiones de delito $)^{86}$.

Por su parte, añade Herrero Herrero que su relación con la comisión de ilícitos vendría a responder a la necesidad de intentar compensar su conflicto interno, indicando que la solvencia a un posible complejo de culpabilidad podría llegar a traducirse en piromanía o cleptomanía, señalando que dicho colectivo no manifestaría ni una amplia ni una grave orientación delictiva ${ }^{87}$.

Las connotaciones de dicha patología se hacen visibles en su traducción jurídica, tal y como expresa la Sentencia del Tribunal Supremo de 4 de febrero de 2013 [RJ 2013\3396] cuando indica la no apreciable eximente de anomalía psíquica entendiendo que pudiera proceder incluso con planificación, lo que disminuiría la impulsividad del sujeto de actuar irrefrenablemente. De manera específica, establece el Tribunal Supremo que «solo en supuestos de excepcional gravedad puede llegar a plantearse la eventual apreciación de una eximente, completa o incompleta, cuando pericialmente se acredite fuera de toda duda una anulación absoluta o cuasi-absoluta de la capacidad de raciocinio o voluntad del acusado. Pero solamente respecto de acciones temporalmente inmediatas al momento en que la oportunidad del juego se presenta y domina la voluntad del agente en torno al acto concreto de jugar, y no respecto de otros actos más lejanos, que requieren cuidadosa planificación, como los realizados en el caso actual, en los que la adicción, (caso de concurrir, que no se ha

\footnotetext{
${ }^{86}$ Ibídem, p.445.

${ }^{87}$ HERRERO HERRERO, C., Tratamiento de Criminología Clínica, Madrid, Dykinson, 2013, p.303
} 
acreditado) actuaría sólo como impulso organizado (racional y dominable) para lograr el futuro placer del juego»».

Esto permitiría diferenciar a quienes presentan una verdadera patología de quienes se escudan en ella para apreciar la inimputabilidad; no obstante, de cualquier forma, en el caso de un sujeto con uno de los citados trastornos que es capaz de arrepentirse de sus actos no sería cuestionable la falta de comprensión de aquellos pues, de otro lado, ¿por qué cabría arrepentirse si desconociera la ilicitud de la acción?

Igualmente a lo anterior, cabría hacer el siguiente planteamiento: si la impulsividad fuera tan importante para el enjuiciamiento de los hechos ¿por qué no valorar en mayor medida los TCI?

La impulsividad en el TDAH sería la sintomatología que pudiera, quizá, plantear mayor debate cuando se alude a la cuestión de la responsabilidad penal pero que, tal y como se ha visto, no se apoyaría en cualquier caso en una ausencia de entendimiento, ya presente el sujeto un diagnóstico de TDAH -al igual que sucede con los TCl-. Pero es más, si quisiera vincularse el TDAH con la inimputabildiad o atenuación de la responsabilidad penal también lo haría con la variable impulsividad o déficit en la autodeterminación de la conducta. Ante ello, debe conocerse que ni siquiera en los propios criterios del DSM podría valorarse su aplicabilidad de manera autónoma, sino por su presencia conjunta con la sintomatología hiperactiva, tal y como se deduce del número de criterios diagnósticos mínimos que deberán reunirse para hablarse de trastorno. Motivo este que desprestigia la posible valoración del TDAH dentro de aquel grupo de anomalías en comparación con los $\mathrm{TCl}$, los cuales centran su sintomatología de manera casi exclusiva en la impulsividad y no son considerados a nivel penal.

\section{CONSIDERACIONES FINALES}


Siguiendo la Sentencia de la Sala de lo Militar del Tribunal Supremo de 14 de enero [RJ2008\1578] en relación al artículo 20.1 CP, «tal como está redactado el actual artículo 20.1 del Código Penal, el orden de comprobación a seguir al efecto de verificar si concurren los requisitos precisos para apreciar una eximente completa o incompleta por anomalías o trastornos psíquicos habrá de comenzar por comprobar que el sujeto activo del delito está afectado por una anomalía o trastorno, en cuyo amplio concepto caben tanto las tradicionalmente admitidas y entre ellas, las psicosis graves, las enfermedades mentales, los retrasos $\mathrm{u}$ oligofrenias como otras Consistentes en trastornos o anomalías psíquicas, con excepción de los episodios provocados por la ingestión de alcohol o el consumo de drogas cuyos efectos eximentes o atenuantes son tratados separadamente por el Código Penalı, a lo que añade, «posteriormente habrá de observarse si tales causas psíquicas anómalas han determinado incapacidad, disminución de la comprensión de la ilicitud de la conducta o de actuar volitivamente en concordancia con tal comprensión y que esa relación causa-efecto haya coincidido temporalmente con la comisión del hecho, interviniendo en su génesis o en las formas de su realización».

Efectivamente ése sería el punto de partida en la valoración de la posible cabida de alguna de las patologías mentales descritas en la CIE-10 y en el DSM-5 dentro del artículo 20, y en su caso 21, del Código Penal. De este modo, ya sea por aplicación de la eximente completa, como de la eximente incompleta o atenuante analógica, la extensión de la aplicabilidad de las circunstancias modificativas de la responsabilidad criminal afectarán a las "anomalías o alteraciones mentales permanentes" - así denominadas por la doctrina penal-, identificadas comúnmente con el conjunto de alteraciones que afectan a las psicosis, neurosis, oligofrenias y psicopatías.

Si bien desde la fórmula legislativa el Código Penal se hace eco de una formulación abierta que no define el concepto de imputabilidad sino en sentido negativo por su derivación expresa al concepto de inimputable (artículo $20 \mathrm{CP}$ ), lo cierto es que también dicha cláusula amplía el catálogo de psicopatologías con posible adhesión a su postulado a partir de la disyuntiva empleada para describir la existencia de una afectación del intelecto "o" volición en grado suficiente. Es precisamente en este punto en el que se detiene la doctrina para referir la 
posible cabida de las patologías mentales previamente anunciadas bajo la contemplación de un modelo mixto, el cual responde a la caracterización del cuadro clínico entendiendo que será de severidad suficiente como para anular, y en su caso disminuir significativamente, las facultades señaladas.

Es cierto que en un primer momento tanto el artículo $20.1 \mathrm{CP}$, como el 21 en sus apartados primero y séptimo, pudieran resultar poco restrictivos en cuanto a su redacción literal, ante lo cual la doctrina penal, y especialmente la jurisprudencia, han permitido establecer los límites de su aplicabilidad. Como ya se indicó, tanto desde un punto de vista como de otro podrían hallarse algunas deficiencias -como podría ser el intercambio en la nomenclatura de las psicopatologías, o su empleo como sinónimos en algunas sentencias-, pero lo cierto es que son dichas posturas las que permiten ir discriminando, con ayuda de otras Ciencias, las alteraciones mentales que mayor beneficio podrían obtener a nivel penal en cuanto a la consecución de la exención para el sujeto diagnosticado de un determinado cuadro clínico.

Tras el examen realizado, una vez valoradas las denominadas "anomalías/alteraciones mentales permanentes", así como su vinculación con el TDAH para dar respuesta a la cuestión sobre su posible cabida dentro del régimen de la inimputabilidad, podrían extraerse las siguientes conclusiones:

1. La impulsividad será el factor criminógeno por excelencia así como el determinante del desarrollo de comportamientos disociales que evolucionen hacia la criminalidad. Ahora bien, lo hará en su consideración de sintomatología externalizante (hiperactividad e impulsividad), pues por sí sola no podría diagnosticarse con un número suficiente de criterios clínicos si no es en presencia de hiperactividad.

Además, habría que resaltar que la aparición del TDAH en el ámbito penalpenitenciario deviene de su necesaria co-ocurrencia con otras alteraciones, pudiendo afirmar que la comorbilidad sería la responsable de dicho resultado, pues muy excepcionalmente lo hará el TDAH como diagnóstico único. Se trata de un dato que no es de extrañar en sujetos con 

presencia en el DSM-5 tras la alusión a la "significación clínica".

2. Se comprueba a su vez que el TDAH por sí solo tiene muy poca cabida en cuanto a la apreciación de la inimputabilidad, incluso en relación a la semi-imputabilidad (eximente incompleta) o a la disminución de la responsabilidad por aplicación de la atenuante analógica. Es más, de considerar en algún momento su apreciación lo será en mayor medida por las implicaciones que supone en la faceta volitiva o la capacidad de autodeterminación del comportamiento, y en ningún caso desde la facultad cognoscitiva.

3. Las psicosis serían el conjunto de alteraciones que mayor aceptación podrían tener en la práctica, principalmente por las repercusiones que en la esfera cognitiva y volitiva suponen. Claro está que en este caso el TDAH, por su propia definición, no presentará una sintomatología que pudiera alcanzar dichos extremos, pues de hacerlo exclusivamente lo hará por la incapacidad de controlar sus acciones debido a la presencia de unos elevados niveles de impulsividad. Pese a ello, los niveles de dicha sintomatolgía externalizante, por lo sí sola, no serán apreciados en términos de circunstancia modificativa de la responsabilidad criminal, siendo distinto que el TDAH aparezca de manera co-ocurrente con aquella alteración.

4. En su vinculación con las neurosis, ya se puso de relieve que dicho concepto ha sido el comúnmente empleado por la doctrina penal para referirse a un conjunto de reacciones anormales que generan angustia o estrés, llegando a limitar la capacidad de actuación, término que, si bien no vigente a día de hoy en los Manuales Internacionales (DSM.5 y ClE-10), sí que se mantiene en el ámbito del Derecho albergando una gran variedad de cuadros clínicos, entre los que se encontrarían, principalmente, la depresión y la ansiedad.

La elevada prevalencia de estos cuadros hace muy posible de hallar su presencia comórbida con el TDAH, siendo también bastante excepcional el hecho de hallarlos en supuestos de exención completa a no ser que su presentación sea capaz de anular la cognición o volición del sujeto, en cuyo caso, la presencia de TDAH no será imprescindible para tomar aquélla decisión. 
5. La oligofrenia o retraso en el desarrollo intelectual permite observar cunado existe una evidentemente merma en la esfera cognitiva o intelectiva que impide o dificulta al individuo actuar con normalidad. En este sentido, dependiendo del grado o severidad de la disfunción, así como de la consideración de la interferencia de la patología como suficientemente significativa o no, así será la exigencia de responsabilidad correspondiente al que hubiera actuado en presencia de tal alteración.

La distinción en niveles de gravedad (leve, moderado, grave y profundo), así como de las áreas afectadas (conceptual, social y práctica), hacen la labor del tribunal sentenciador más fácil a la hora de discernir sobre la posible aplicabilidad del artículo $20.1 \mathrm{CP}$ o, por su parte, de alguno de los apartados comprendidos en el artículo 21 CP. A modo de ejemplo, la dependencia absoluta de otras personas, así como la elevada limitación en la comprensión simbólica (gestos), permitirá apreciar la existencia de un tipo de discapacidad intelectual que influye significativamente en la vida del sujeto determinando una muy deficiente y limitada capacidad cognitiva.

Al igual que sucede con las restantes alteraciones, el TDAH podrá presentarse comórbidamente con esta psicopatología, debiendo quedar corroborada la relación causal de esta última con el hecho en cuestión a efectos de la culpabilidad. En cualquier caso, el TDAH en presencia de una discapacidad intelectual ocupará el segundo plano a efectos de exención penal, por no venir expresamente señalado por la doctrina penal; es más, si bien es cierto que podría incluso ayudar a afianzar una decisión jurisprudencial, no será precisamente este diagnóstico el que conduzca en primea instancia a dicho resultado.

6. En lo que atañe a los trastornos de la personalidad, quizá uno de los temas más controvertidos en cuanto a las "psicopatías" -así denominadas por la doctrina penal y Tribunales españoles-, hace referencia a la cuestión de su posible inclusión bajo el párrafo primero del artículo $20 \mathrm{CP}$, pues mientras las restantes alteraciones (psicosis, neurosis y oligofrenias) pudieran parecer menos dudosas, en lo que atañe a estos trastornos la cuestión es muy discutida. 
De una parte, en principio la generalidad en la aplicación de la exención no puede apreciarse en ninguna psicopatología, y menos aún en aquellas en las que sería tan cuestionable su introducción dentro del artículo 20.1 CP. A modo de ejemplo indica la Sentencia del Tribunal Supremo 831/2001, de 14 de mayo [RJ 2001\10313] que «la doctrina jurisprudencial la relevancia de los trastornos de la personalidad en la imputabilidad no responde a una regla generalı, a lo que en relación a los efectos sobre la culpabilidad define la Sentencia del Tribunal Supremo 696/2004, de 27 de mayo [RJ 2004\3798] que «en general se ha entendido que los trastornos de la personalidad no calificados de graves o asociados a otras patologías relevantes no dan lugar a una exención completa o incompleta de la responsabilidad, sino en todo caso a una atenuación simple y solo en aquellos casos en los que se haya podido establecer la relación entre el trastorno y el hecho cometido».

A ello se une que la jurisprudencia no sea siempre pacífica en el sentido de su pronunciamiento, como pudiera aparentemente desprenderse de la Sentencia del Tribunal Supremo 80/2015, de 6 de febrero [RJ 2015\515] y la Sentencia del Tribunal Supremo 633/2014, de 14 de octubre [RJ2014\4725], en comparación con la Sentencia de la Audiencia Provincial de Sevilla 251/2009, de 14 de mayo [JUR 2009\312941], previamente mencionadas.

La praxis refiere que efectivamente se viene apreciando, una vez queda efectivamente corroborada, la atenuante analógica, reservando la eximente incompleta -que no completa-, para aquellos casos en los que el cuadro revista una especial gravedad o venga asociado a otras alteraciones, normalmente a más de una (oligofrenia, alcoholismo, etc.)

Como se ha podido apreciar, la presencia de TDAH en la infancia podrá llegar a relacionarse con el desarrollo posterior de un trastorno de la personalidad, comúnmente muy mediatizado por la existencia de un trastorno oposicionista-desafiante o de conducta. Concretamente, de entre aquellas alteraciones, las que mayor vinculación podrían presentar con el TDAH aludirían al TAP y al TLP, siendo precisamente el detonante común la sintomatología externalizante. 
Traída la cuestión al ámbito jurisprudencial, se aprecia que dichas alteraciones, por sí mismas, son de muy compleja observancia por los tribunales, a pesar de estar definidas de manera específica por la propia doctrina penal. En cualquier caso, ya se indicaron los matices específicos de estas psicopatologías, así como los criterios a seguir en la posible cabida de la inimputabilidad, semi-imputabildiad o disminución de responsabilidad (atenuante analógica), respecto a las mismas.

En este contexto, el TDAH podrá beneficiarse de la aplicación de aquellas circunstancias -principalmente la última-, cuando los TP de por sí lo demanden, lo que generalmente también hacen en comorbilidad o en presencia de diagnóstico dual o múltiple. Pero claro está, ¿por qué querer incluir el TDAH con el beneficio del 20.1 CP cuando el TLP -a modo de ejemplo-, presenta una sintomatología bastante más disfuncional, crónica y severa y no se aprecia como tal?

7. En lo que respecta a otros cuadros, como sería el caso de aquellos relacionados con sustancias, lo cierto es que estas alteraciones han propiciado que en diversas ocasiones el tribunal sentenciador se decantara por la aplicación de un beneficio penal mayor en quien presentara un determinado cuadro clínico y estas alteraciones apareciesen coocurrentemente. Además, no es infrecuente su presencia en el ámbito penal, sobre todo desde el punto de vista legislativo, para lo cual su importancia queda reiterada en los artículos 20 y $21 \mathrm{CP}$.

Podría definirse como una alteración clínica de evidente valor criminógeno, tal y como lo ponen de manifiesto diversas investigaciones al reafirmar el tradicional vínculo consumo de sustancias-criminalidad; pero es más, sus consecuencias sobre la conducta se han hecho tan patentes que su traducción a efectos penales no ha hecho sino incorporarla como una circunstancia capaz de afectar a la cognición y/o volición.

En relación a los $\mathrm{TCl}$ habría que decir que, a nivel teórico, en determinadas ocasiones se han llegado a admitir dentro de las neurosis, siendo muy excepcional de apreciar en la práctica si no es por atenuante analógica y de manera comórbida. Ahora bien, siendo tan 
restrictiva su aplicación y siendo definidos como alteración de la autodeterminación o trastornos de los impulsos, ¿cómo podría tener cabida el TDAH cuando solo lo haría en su sintomatología externalizante y, concretamente, desde la variable impulsividad?

En definitiva, la diversidad de cuadros clínicos, específicamente de sintomatología presente, puede hacer que se determine la inimputabilidad por un lado, e imputabilidad por otro, para dos sujetos que aparentemente pudieran presentar el mismo diagnóstico. Así, al igual que dos calificaciones clínicas pueden recibir distinto tratamiento penal, en el ámbito psicológico también podría hallarse un tratamiento diferente en pacientes con idéntico diagnóstico. De esta forma, el personalizar la intervención se traduce para el Derecho penal en la valoración individual de las circunstancias del reo, para el cual podrá serle o no apreciada la exención de responsabilidad atendiendo a la relación de la psicopatología con el acto ilícito en cuestión.

En lo que respecta a la concreta cuestión de la apreciación de alguna de las circunstancias modificativas de la responsabilidad criminal sobre el TDAH, y respondiendo así a la hipótesis de partida que se planteó en su momento, se podría admitir que dicho trastorno no goza de circunstancias especiales respecto a otras psicopatologías; es más, incluso al contrario, pocas veces podrá llegar a apreciarse como exención o disminución penal si no es por comorbilidad diagnóstica o, en su caso, por fallo denominativo en cuanto a su confusión con otras alteraciones (p.ej. TAP).

De lo que no cabe duda es de que la doctrina penal determina a nivel teórico un conjunto de cuadros clínicos cuya afectación cognitiva y volitiva pudiera determinar la apreciación de artículo $20 \mathrm{CP}$ o, en su caso, del $21 \mathrm{CP}$, y ante lo cual la jurisprudencia determina o especifica en qué condiciones, y cuáles de ellos por su especial intensidad sintomática, reunirán los criterios suficientes como para serles apreciadas aquellas circunstancias. 
Precisamente el TDAH no destaca por su presencia en cuanto a la duda sobre la posible

exigencia de responsabilidad criminal, ya que el único determinante que en mayor medida podría quedar vinculado con la rebaja penal sobre el juicio de culpabilidad lo sería la sintomatología externalizante, concretamente la impulsividad. Pese a ello, de ordinario su manifestación se aparta de la severidad exigible por los tribunales españoles para apreciar la inimputabilidad o semi-imputabilidad, llegando a dicha consideración, así como a la disminución de la pena (atenuante analógica), cuando se presenta de manera co-ocurrente con otras alteraciones o cuadros clínicos que, por su gravedad y afectación en diversas áreas de la vida del sujeto, con frecuencia sí son valorados a efectos de la cuestión de imputabilidadinimputabilidad (como sería el caso de la psicosis) por las consecuencias cognitivo-volitivas que producen.

BIBLIOGRAFÍA

AGUILAR CÁRCELES, El Trastorno por Déficit de Atención e Hiperactividad (TDAH). Aspectos Jurídico-penales, psicológicos y criminológicos, Madrid, Dykinson, 2014.

AGUILAR CÁRCELES, M.M., «Psicopatía: actuación desde la Criminología y del Dereecho penalpenitenciario»», en D.L. Morillas Fernández (Dir.) y Rodríguez Ferrández (Coord.), Criminología y Ejecución de penas, Murcia, EDITUM, 2014.

ÁLVAREZ, H.K. and OLLENDICK, T.H., «Individual and Psychosocial Risk Factors», in Cecilia A. Essau, Conduct and Oppositional Defiant Disorders. Epidemiology, Risk Factors, and Treatment, New Jersey, Lawrence Erlbraum Associates, 2003.

AMERICAN PSYCHIATRIC ASSOCIATION (APA), Diagnostic and Statistical Manual of Mental Disorders, Fifth Edition (DSM-5), Washington D.C., American Psychiatric Association, 2013.

ANCKARSÄTER， H.; STAHLBERG， O.; LARSON， T.; HAKANSSON， C.; JUTBLAD, S.B.; NIKLASSON, L.; NYDÉN, A.; WENTZ, E.; WESTERGREN, S.; CLONINGER, C.R.; GILLBERG, C. and RASTAM, M., 
«The Impact of ADHD and Autism Spectrum Disorders on Temperament, Character, and Personality Development», The American Journal of Psychiatry, Vol.163, $N^{o} .7,2006$.

BARBUDO DEL CURA, E.; CORREAS LAUFFER, J. y GUTIÉRREZ DEL ÁLAMO, F.J., «Caracteriología del adulto con trastorno por déficit de atención e hiperactividad "), en Francisco Javier Quintero Gutiérrez del Álamo, Javier Correas Lauffer y Francisco Javier Quintero Lumbreras, Trastorno de déficit de atención e hiperactividad (TDAH) a lo largo de la vida, Elsevier Masson, 2009.

BARKLEY, R.A., «Primary Symptoms, Diagnostic Criteria, Prevalence, and Gender Differences», in Russel A. Barkley, Attention-Deficit Hyperactivity Disorder. A Handbook for Diagnosis and Treatment, ( $3^{\text {rd }}$ Edition), London, The Guildford Press, 2006.

BIEDERMAN, J.; FARAONE, S.V.; KEENAN, K.; BENJAMIN, J.; KRIFCHER, B.; MOORE, C.; SPRCIH-BUCKMINSTER, S.; UGAGLIA, K.; JELLINEK, M.S. and STEINGARD, R., «Further evidence for family- genetic risk factors in attention deficit disorder: patterns of comorbidity in probands and relatives in psychiatrically and pediatrically referred samples», Archives of General Psychiatry, Vol.49, 1992, pp.728-738.

BIEDERMAN, J.; FARAONE, S.V.; MICK, E. and LELON, E., «Psychiatric comorbidity among referred juveniles with major depression: fact or artifact?», Journal of the American Academy of Child \& Adolescent Psychiatry, Vol.34, 1995, pp.579-590.

CABALLO, V.E., "Conceptos actuales sobre los trastornos de la personalidad», en Vicente E. Caballo (Coord.), Manual de trastornos de la personalidad. Descripción, evaluación y tratamiento, Madrid, Síntesis, 2009.

CARRASO GÓMEZ, J. J. y MAZA MARTíN, J. M., Manual de Psiquiatría Legal y Forense, Madrid, La Ley-Actualidad, 2010.

CEREZO MIR, J., Curso de Derecho Penal Español. Parte General (II). Teoría jurídica del delito (6a Edición), Madrid, Tecnos, 1998.

CHRONIS-TUSCANO; A.; MOLINA, B.; PELHAM, W.; APPLEGATE, B. and DAHLKE, A., «Children with ADHD at increased risk for depression and suicidal thoughts as adolescents $)$, University of Chicago, 2010. 
CLIMENT DURÁN, C., Código Penal. Jurisprudencia Sistematizada (4ạ Edición), Valencia: Tirant lo Blanch, 2011.

COBO Del ROSAL, M. y VIVES ANTÓN, T. S., Derecho Penal. Parte General (4ạ Edición), Valencia, Tirant lo Blanch, 1999.

COHEN, P.; COHEN, J.; KASEN, S., VELEZ, C.N.; HARTMARK, C.; JOHNSON, J.; ROJAS, M.; BROOK, J. and STREUNING, E., «An epidemiological study of disorders in late childhood and adolescence-l. Age- and gender-specific prevalence»), Child Psychological Psychiatry, Vol.34, №.6, 1993, pp.851-867.

\section{CROSS-DISORDER GROUP OF THE PSYCHIATRIC GENOMICS CONSORTIUM,} «Genetic relationship between five psychiatric disorders estimated from genome-wide SNPs»», Nature Genetics, Vol.45, 2013, pp.984-994.

DE CORRAL, P., «Trastorno antisocial de la personalidad», en E. Echeburúa, Personalidades violentas, Madrid, Ediciones Pirámide, 2009.

ECHEBURÚA, E., Personalidades violentas, Madrid, Ediciones Pirámide, 2009.

EY, H., Tratado de Psiquiatría, Barcelona, Masson, 2006.

FONSECA MORALES, G.M., La anomalía o alteración psíquica como eximente o atenuante de la responsabilidad criminal, Madrid, Dykinson, 2007.

GARCÍA ANDRADE, J.A., Psiquiatría criminal y forense (2 2 Edición), Madrid, Centro de Estudios Ramón Areces, 2002.

GEEKIE, J. y READ, J., El sentido de la locura, Barcelona: Herder Editorial, 2012.

GISBERT CALABUIG, J.A., Medicina Legal y Toxicología, Barcelona, Masson, 2004.

HALMOY, S.; KLUNGSOYR, K.; SKJAEREN, R. \& HAAVIK, J., «Pre- and perinatal risk factors in adults with attention-deficit/hyperactivity disorderı, Biological Psychiatry, Vol.71, 2012, pp.474-481.

HERRERO HERRERO, C., Tratamiento de Criminología Clínica, Madrid, Dykinson, 2013.

JIMÉNEZ DÍAZ, M.J. y FONSECA MORALES, G.M., Trastornos de la Personalidad (psicopatías). Tratamiento científico y jurisprudencial (2a Edición), Madrid, CESEJ-Ediciones, 2007, p.45.

KINDT, H., "Zur Entstehung und Entwicklung des Psychose-Begriffes», Fortsch. Neurol. Psychiat., Vol.42, 1974, pp.453-464. 
LEWINSOHN, P.M.; ROHDE, P. and SEELEY, J.R., «Psychosocial risk factors for future adolescent suicide attemptsı, Journal of Counsulting and Clinical Psychology, Vol. 62, 11994, 297-305.

LÓPEZ BARJA DE QUIROGA, J. (Dir.), Código Penal con jurisprudencia sistematizada (5ạ Edición), Valencia: Tirant lo Blanch, 2014.

LÓPEZ-IBOR, J.J., La personalidad en Medicina y sus trastornos, Madrid, Real Academia Nacional de Medicina, 1993.

MAYES, R.; BAGWELL, C. and ERKULWATER, J., Medicating Children. ADHD and Pediatric Mental Health, Cambridge, Harvard University Press, 2009.

MIR PUIG, S., Derecho Penal. Parte General (9 ${ }^{\text {a }}$ Edición), Barcelona, Editorial Reppertor, 2011.

MORILLAS FERNÁNDEZ, D.L. y AGUILAR CÁRCELES, M.M., «El inicio de la carrera criminal en menores infractores con Trastorno por Déficit de Atención e Hiperactividad (TDAH)»), en F. Miró Llinares, J.R. Agustina Sanllehí, J.E. Medina Sarmiento y L. Summers (Eds.), Crimen, oportunidad y vida diaria. Libro Homenaje al Profesor Dr. Marcus Felson, Madrid, Dykinson, 2014.

MORILLAS FERNÁNDEZ, D. L., «Aspectos criminológico de los psicópatas y asesinos en serie », Cuadernos de Política Criminal, Vol.77, 2002, pp.416 y 417.

MUÑOZ CONDE, F. y GARCÍA ARÁN, M., Derecho Penal. Parte General (8a Edición), Valencia, Tirant lo Blanch, 2010.

ORTS BERNEGUER, E. y GONZÁLEZ CUSSAC, J. L., Compendio de Derecho Penal. Parte General. 2ª Edición actualizada conforma a la LO 5/2010, Valencia, Tirant lo Blanch, 2010.

PHILIPSEN, A. «Differential diagnosis and comorbidity of attention-deficit/hyperactivity disorder (ADHD) and borderline personality disorder (BDP) in adults», European Archives of Psychiatry and Clinical Neuroscience, Vol.256, №.1, 2006, pp.142 y ss.

POPPER, C.W.; GAMMON, G.D.; WEST, S.A. and BAILEY, C.E.; «Disorders Usually First Diagnosed in Infancy, Childhood and Adolescence»), in Robert E. Hales and Stuart C. Yudofsky, Textbook of Clinical Psychiatry (4 ${ }^{\text {th }}$ Edition), Washington, The American Psychiatry Publishing, 2003. 
POZUECO ROMERO, ROMERO GUILLENAS y CASAS BARQUERO, N., «Psicopatía, violencia y criminalidad: un análisis psicológico-forense, psiquiátrico-legal y criminológico (Parte II) », Cuadernos de Medicina Forense, Vol.17, №.4, 2011, pp.175-192.

QUINTERO OLIVARES, G., Locos y culpables, Navarra: Aranzadi, 1999.

RAMOS-QUIROGA, J.A.; BOSCH-MUNSÓ, R.; CASTELLS-CERVELLÓ, X.; NOGUEIRAMORAIS, M.; GARCÍA-GIMÉNEZ, E. y CASAS-BRUGUÉ, M., «Trastorno por déficit de atención con hiperactividad en adultos: caracterización clínica y terapéutica», Revista de Neurología, Vol.42, №.10, 2006, pp.600-606.

SOUTULLO ESPERÓN, C. y DíEZ SUÁREZ, A., Manual de Diagnóstico y Tratamiento del TDAH, Madrid, Panamericana, 2007.

SPERANZA, M.; REVAH-LEVY, A.; CORTESE, S.; FALISSARD, B.; PHAM-SCOTTEZ, A. and CORCOS, M., «ADHD in adolescents with borderline personality disorder», BMC Psychiatry, Vol.11, 2011.

TIFFON NONIS, B.N.; ARROYO FERNÁNDEZ, A. y SARRATO MARTÍNEZ, L., «UUna trimorbilidad forense emergente: TLP + TCI + TDAH y su correlato con el abuso de sustancias tóxicas», en B.N. Tiffon Nonis, Manual de actuación profesional en Psicopatología Clínica, Criminal y Forense: una dimensión Jurídico-Legal, Barcelona, Bosch-Penal, 2009.

TIZON, J. L. et al., « Factores de riesgo para padecer trastornos psicóticos: ¿Es posible realizar una detección preventiva?»), Clínica y Salud, Vol.19, №.1, 2008, pp. 27-58.

URRUELA MORA, A., Imputabilidad penal y anomalía o alteración psíquica, Granada, Comares, 2003.

WESTMORELAND, P.; GUNTER, T.; LOVELESS, P.; ALLEN, J.; SIELENI, B. and BLACK, D.W., «Attention Deficit Hyperactivity Disorder in Men and Women Newly Committed to Prison. Clinical Characteristics, Psychiatric Comorbidity, and Quality of Life», International Journal of Offender Therapy and Comparative Criminology, Vol.54, №.3, 2010, pp.361-377.

WILLIAM, N.M.; ZAHARAIEVA, I.; MARTIN, A.; LANGLEY, K.; MANTRIPRAGADA, K.; FOSSDAL, R.; STEFANSSON, H.; MAGNUSSON, P.; GUDMUNDSSON, O.O.; GUSTAFSSON, O.; HOMANS, P.; OEWN, M.J.; O'DONOVAN, M. and THAPAR, A., «Rare chromosomal 
deletions and duplications in attention-deficit hyperactivity disorder: a genome-wide analysis», The Lancet, Vol.376, №.9750, 2010, pp.1401-1408.

WORLD HEALTH ORGANIZATION (WHO), International Statistical Classification of Diseases and Related Health Problems, Tenth Revision (ICD-10), World Health Organization, 1992.

YOO, H.I.; CHO, S.C.; KIM, B.N.; KIM, S.Y.; SHIN, M.S. and HONG, K.E., «Psychiatric morbidity of second and third grade primary school children in Korea», Child Psychiatry and Human Development, Vol.36, №.2, 2005, pp.215-225

ZAPOLSKI, T.C.B.; SETTLES, R.E.; CYDERS, M.A. and SMITH, G.T, «Borderline Personality Disorder, Bulimia Nervosa, Antisocial Personality Disorder, ADHD, Substance Use: Common Threads, Common Treatment Needs, and the Nature of Impulsivity», Independent Practitioner, Vol.30, №.1, 2010, pp.20-23. 